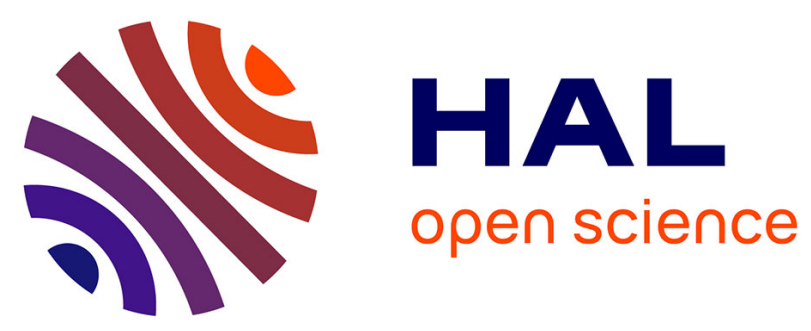

\title{
Wind hazard and turbulence monitoring at airports with lidar, radar and Mode-S downlinks: The UFO Project
} Albert C. P. Oude Nijhuis, Ludovic P. Thobois, Frédéric Barbaresco, Siebren de Haan, Agnès Dolfi-Bouteyre, Dmitry Kovalev, Oleg A. Krasnov, Danielle Vanhoenacker-Janvier, Richard Wilson, Alexander G. Yarovoy

\section{To cite this version:}

Albert C. P. Oude Nijhuis, Ludovic P. Thobois, Frédéric Barbaresco, Siebren de Haan, Agnès DolfiBouteyre, et al.. Wind hazard and turbulence monitoring at airports with lidar, radar and Mode-S downlinks: The UFO Project. Bulletin of the American Meteorological Society, 2018, 99 (11), pp.22752293. 10.1175/BAMS-D-15-00295.1 . insu-01804083

\section{HAL Id: insu-01804083 \\ https://hal-insu.archives-ouvertes.fr/insu-01804083}

Submitted on 20 May 2019

HAL is a multi-disciplinary open access archive for the deposit and dissemination of scientific research documents, whether they are published or not. The documents may come from teaching and research institutions in France or abroad, or from public or private research centers.
L'archive ouverte pluridisciplinaire HAL, est destinée au dépôt et à la diffusion de documents scientifiques de niveau recherche, publiés ou non, émanant des établissements d'enseignement et de recherche français ou étrangers, des laboratoires publics ou privés. 


\title{
WIND HAZARD AND TURBULENCE MONITORING AT AIRPORTS WITH LIDAR, RADAR, AND MODE-S DOWNLINKS The UFO Project
}

\author{
A. C. P. Oude Nijhuis, L. P. Thobois, F. Barbaresco, S. De Haan, A. Dolfi-Bouteyre, D. Kovalev, \\ O. A. Krasnov, D. Vanhoenacker-Janvier, R. Wilson, and A. G. Yarovoy
}

This article presents the prospects of measurement systems for wind hazards and turbulence at airports, which have been explored in the Ultrafast Wind Sensors project.

A ir traffic stakeholders face a doubling of the worldwide air traffic within the next 20 years, while at the same time they have to improve safety and efficiency (ICAO 2014). Regarding safety, wind hazards play an important role, especially during the takeoff and landing phases, where the majority of accidents occur (Boeing 2013). Studies have shown that adverse weather has a major impact on airport operations, causing about half of the air navigation system (ANS)-related accidents in Europe (EUROCONTROL 2013) and contributing significantly to delays (Klein et al. 2009; Kulesa 2003). Airport capacities are also limited by regulations for minimum distance separations between aircraft (ICAO 2007). These distances have been defined for the worst weather conditions, which are low wind speed and/or low turbulence intensities that can result in the longest-lasting wake turbulence, to avoid the risks for a follower aircraft to encounter the wake turbulence from the leader aircraft.

Nowadays, wake turbulence regulations from the International Civil Aviation Organization (ICAO) on distance separation between aircraft have been improved, via the U.S. and European Union (EU) Wake Vortex Recategorisation (RECAT) projects by refining the aircraft wake turbulence categories. To further increase airport capacity, the dynamic distance separations should be adjusted with weather conditions. Currently, such concepts are being developed. An example is time-based separation (TBS) in Europe, which is already deployed at London's Heathrow Airport (Morris et al. 2013). In the United States, wake turbulence mitigation for arrivals (WTMA) is developed (Williams et al. 2008). These concepts usually take the headwind and crosswind conditions into account to adapt the wake turbulence distance separations. More advanced dynamic distance separation concepts employ the energy dissipation rate (EDR), which is used as a measure for turbulence intensity and sometimes called eddy dissipation rate (Chan 2011; Nastrom and Eaton 1997), as an input parameter for wake vortex lifetime estimation (Singhal 2014; Holzäpfel 2006). Therefore, monitoring and forecasting wind and turbulence conditions 
in the final approach path can improve air traffic safety and efficiency.

In current airport operations, local wind hazards are determined by the local weather forecast, in situ surface measurements, and/or weather radars providing information on wind profiles, surface wind speed, surface wind direction, and wind shear. Surface wind speed and direction are obtained from a network of anemometers installed at 10-m height (ICAO 2016; WMO 2010). At airports where wind shear is a concern, the low-level wind shear alert system (LLWAS) is employed, which uses a network of anemometers around airports to estimate the horizontal wind shear (Stoll 1991). Doppler weather radars have been developed in different bands (C, S, X) that can detect hazardous wind shear, but because of their measurement principle they require sufficient reflectors, which make them predominantly available under rainy conditions and not during clear conditions.

In advanced dynamic separation concepts, accurate and frequent wind and turbulence intensity observations are needed in specific areas, such as the aircraft approach and takeoff flight paths. The LLWAS and in situ sonic anemometer wind measurements are limited for this purpose, as they represent surface measurements, which lack the representativeness needed for the terminal maneuvering area (TMA; e.g., Wieringa 1980). To achieve accurate wind information at higher altitudes, measurements along the aircraft approach and takeoff flight paths are desired. In addition, for improving numerical weather prediction (NWP) models, more observations for data assimilation are required (Illingworth et al. 2015).

The Ultrafast Wind Sensors (UFO) project has been launched to develop a unique set of wind vector

AfFiliations: OUde NiJHUIS, KRASNOV, AND YAROVOY-Delft University of Technology, Delft, Netherlands; TновоIS-Leosphere, Orsay, France; BARBARESCO-Thales Air Systems, Rungis, France; DE HAAN-Royal Netherlands Meteorological Institute (KNMI), De Bilt, Netherlands; Dolfi-Bouteyre-ONERA, Palaiseau, France; KovaleV AND VANHOENACKER-JANVIER-Université catholique de Louvain, Louvain-la-Neuve, Belgium; WILSON_LATMOS/IPSL, Sorbonne Université, Paris, France CORRESPONDING AUTHOR: Albert Oude Nijhuis, albertoudenijhuis@gmail.com

The abstract for this article can be found in this issue, following the table of contents.

DOI:10.II75/BAMS-D-I5-00295.I

In final form 12 May 2018

C2018 American Meteorological Society

For information regarding reuse of this content and general copyright information, consult the AMS Copyright Policy. and turbulence intensity measurement systems for wake-vortex hazard mitigation (Thobois et al. 2015). The first goal of the UFO project is to define and develop an optimal combination of advanced measurement systems that 1) allows for the observation of wind vectors and turbulence intensities during all weather conditions and 2) satisfies current and future requirements for wind hazard and turbulence monitoring in aviation, including the advanced dynamic distance separation concepts. The difficulty here lies in the fact that the ground-based remote sensors have intrinsic limitations in terms of accuracy, range, and data availability under different weather conditions. The second goal of the UFO project consists of determining how to use these measurements for improving local weather forecasts, which implies higher-resolution NWP models than the ones currently used operationally.

The measurement systems that have been used in the UFO project to achieve these goals are 1) an electronic scanning X-band radar, 2) a scanning coherent Doppler lidar at $1.5 \mu \mathrm{m}, 3$ ) an X-band profiling radar, 4) a profiling lidar, and 5) Mode-S downlinks. For all these measurement systems, wind vector and turbulence intensity retrieval techniques were adapted and further developed when necessary. These retrieval techniques have been validated by simulations and were applied during trials at Toulouse-Blagnac Airport, Blagnac, France.. The accuracy of wind vectors is assessed by comparison to in situ measurements from a research aircraft and by a comparison to NWP model output. Finally, the performance of state-of-the-art NWP models is tested by an observing system experiment (OSE), where the new observations are assimilated.

This article presents the main achievements of the UFO project. In the next section, the measurement system objectives, given the current and future requirements for monitoring of wind hazards in aviation, are defined. Consequently, the measurement systems are presented for measuring wind vectors and turbulence intensities. In the third section, wind vector and turbulence intensity retrieval techniques for each measurement system will be described, including a validation for clear-air radar-based EDR estimation via large-eddy simulations (LESs). In the fourth section, trials with the added measurement systems at Toulouse-Blagnac Airport are presented, and the retrieved wind vectors and turbulence intensities are compared for (almost) horizontally scanning and vertical profiling measurements, including measurements from a research aircraft. In the fifth section, the results of an OSE are presented, validating the added value of lidar data ingestion in high-resolution NWP 


\begin{tabular}{|l|c|c|c|c|c|}
\hline \multicolumn{6}{|c|}{ TABLE I. Measurement system objectives for wind hazard surveying. } \\
\hline $\begin{array}{c}\text { Area of } \\
\text { interest }\end{array}$ & Needs & $\begin{array}{c}\text { Horizontal } \\
\text { range } \mathbf{( k m )}\end{array}$ & $\begin{array}{c}\text { Vertical } \\
\text { range } \mathbf{( k m )}\end{array}$ & $\begin{array}{c}\text { Spatial } \\
\text { scale } \mathbf{( m )}\end{array}$ & $\begin{array}{c}\text { Revisit } \\
\text { time (s) }\end{array}$ \\
\hline Vertical profile & Wind/EDR & - & 0.5 & 20 & 10 \\
\hline Glide path profile & Wind/EDR & 10 & 0.5 & 400 & 60 \\
\hline $360^{\circ}$ mapping & Wind/EDR & 10 & 0.5 & 400 & 600 \\
\hline $360^{\circ}$ mapping & Wind shear & $7-8$ & 0.5 & 400 & 180 \\
\hline
\end{tabular}

The distance of this glide path measurement should be $10 \mathrm{~km}$ to reach an altitude of $500 \mathrm{~m}$ with a glide slope of $3^{\circ}$. The resolution along the glide path should be $400 \mathrm{~m}$ to have a $20-\mathrm{m}$ vertical resolution on such a glide slope. Considering

models. Finally, the conclusions will be presented, which include recommendations for the new measurement systems.

\section{UFO WIND HAZARD MEASUREMENT} SYSTEMS. Measurement system objectives. The requirements for different applications regarding surveying of wind hazards at airports have been generalized as measurement system objectives in the UFO project and are given in Table 1 . The identified future needs are 1) estimation of vertical profiles of wind vectors and turbulence intensity; 2) estimation of wind vectors and turbulence intensity in the approach and takeoff paths; and 3) $360^{\circ}$ mapping of wind vectors, turbulence intensity, and wind shear. The horizontal and vertical range, spatial resolution, and revisit times have been based on current airport operation standards for the estimation of wind vectors and wind shear (e.g., ICAO 2005) and were updated with the needs of future weather awareness and future dynamic separation concepts. Measurements below $500 \mathrm{~m}$ above ground level are essential, because the wind dynamics in the atmospheric boundary layer $(\mathrm{ABL})$ are rather complex and cannot easily be forecasted by NWP models (all elevations hereafter are above ground level; Robasky and Clark 2008; Salonen et al. 2011). In addition, mapping $360^{\circ}$ views around the airport improves weather awareness (e.g., Chan 2011). Future dynamic separation concepts rely on estimation of wind vectors and turbulence intensity in the approach and takeoff paths. the typical frequency of landings and takeoffs, wind and EDR profiles should be refreshed every minute. Further, note that the numbers in Table 1 are not strict as each airport configuration differs and has their own specific air traffic monitoring (ATM) system and local aviation regulations.

Electronic scanning $X$-band radar. For many years, there has been a growing interest in the development of weather radars for local weather monitoring (Wolfson et al. 1990). The advantages of X-band radars compared to other bands like $\mathrm{C}$ band or $\mathrm{S}$ band are increased range resolution and reduced costs. A drawback of X-band radars compared to S-band or $\mathrm{C}$-band radars is that the maximal range is reduced, because of higher attenuation.

Within the UFO project, an X-band solid-state electronic scanning radar has been developed by Thales to monitor wind hazards (Fig. 1a). This radar has been designed around high-performance hardware: a full solid-state $600-\mathrm{W}$ modular transmitter that enables graceful degradation. Graceful degradation means that in case of failure of the transmitter module, operation continues at a lower power step. The radar is composed of an electronic beam-steering antenna, designed for monitoring wake vortices in short-range mode (up to $2 \mathrm{~km}$, high update rate of $7.5 \mathrm{~s}$ ) and for wind vectors and turbulence intensity measurements in far-range mode (up to $60 \mathrm{~km}$ ). Its main characteristics are a slotted waveguide, a pencil beam with a full width at half maximum (FWHM) (a)

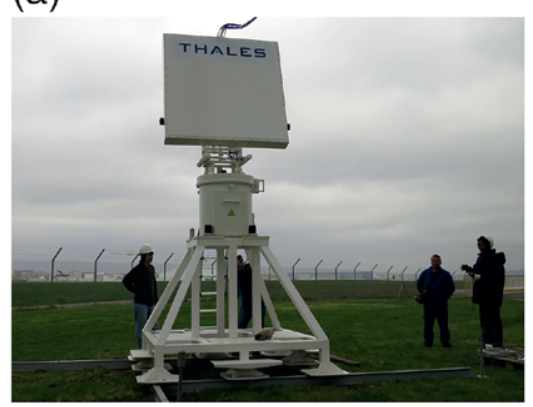

(b)

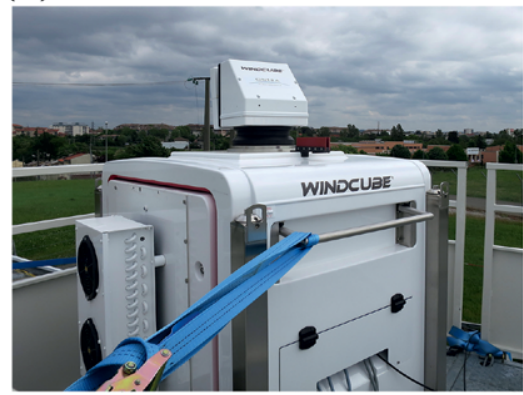

(c)

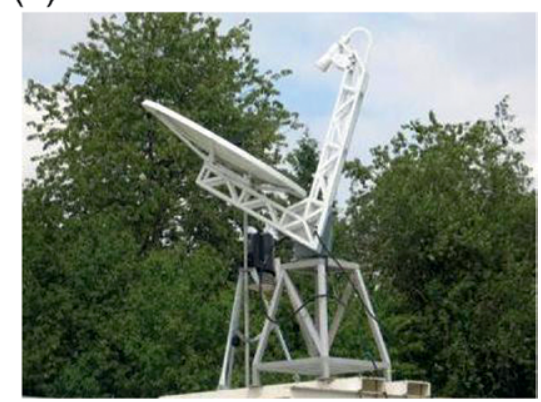

FIG. I. Measurement systems in the UFO project: (a) the X-band Thales scanning radar, (b) the Leosphere scanning lidar, and (c) the X-band CURIE profiling radar. 
of $1.8^{\circ}$, and $40-\mathrm{dB}$ directivity. The radar has a range resolution of $5 \mathrm{~m}$ in short-range mode, achieved by pulse compression, that allows for the discrimination of wake vortices (Barbaresco et al. 2015). The far-range mode has a 50-m resolution.

I.54- $\mu m$ scanning coherent Doppler lidar. Scanning pulsed Doppler lidars have been developed for many years, having as their main application the monitoring of wind under clear-air conditions (Chan et al. 2006). Today, lidars are increasingly used in aviation operations, in particular wind and wind shear monitoring (Dolfi-Bouteyre et al. 2009). They have become the reference measurement system for wake vortex measurements (Kameyama et al. 2007; Zhang et al. 2014; Cariou et al. 2006; Köpp et al. 2005; Holzäpfel et al. 2003; Gerz et al. 2002). Most of the wind lidars use heterodyne detection. They emit in the nearinfrared region between 1.5 and $2 \mu \mathrm{m}$, which has the following advantages: 1) efficient lasers and amplifiers are available at those wavelengths thanks to erbium-ytterbium or holmium-thulium dopants; 2) relatively high laser energy can be used while ensuring eye safety; and 3) for some specific frequencies, atmospheric transmission is good. Nevertheless, compared to radars, atmospheric attenuation in the near-infrared is much higher for lidars, which explains their short-range performance of typically $10 \mathrm{~km}$ for the highest-power lidars in clear air.

Pulsed master oscillator power all-fiber amplifier (MOPFA) technology is most adaptive for operational uses with high efficiency, robustness, and cost effectiveness (Dolfi-Bouteyre et al. 2009; Kameyama et al. 2007). Still, as of just several years ago, the maximum peak power of the fiber amplifier was limited to a few hundred watts, due to stimulated Brillouin scattering (SBS; Kulcsar et al. 2003). Even if the existing laser power was sufficient for a requirement such as wind profiling, wind shear detection, or wake vortex detection, it is not sufficient for the objectives of the UFO project, which require at least the far range of $10 \mathrm{~km}$ and revisit times of $10 \mathrm{~s}$. For the UFO project, developments have been carried out by the use of two stages of amplification and special optical fibers, which increases the maximum peak power of fiber amplifiers. The high-peakpower laser source has, consequently, been integrated into a compact existing enclosure, which is typically used for commercial lidar products (Fig. 1b). Several experiments have been performed that demonstrated the enhanced capabilities of the lidar prototype, such as a doubling of the maximum peak power (Lombard et al. 2015). The obtained performances are equal to the UFO measurement system objectives.
Radar and lidar profilers. Two atmospheric profiling remote sensors were used during the UFO experiments: an X-band radar and a Doppler lidar. These measurement systems have the aim to characterize vertical profiles of wind and turbulence parameters in the lower part of the ABL.

X-band CURIE radar. The Laboratoire Atmosphere, Milieux, Observations Spatiales (LATMOS) from Université Pierre et Marie Curie (UPMC) developed and operated an X-band radar, named CURIE (an acronym for Canopy Urban Research on Interactions and Exchanges; Al-Sakka et al. 2009). It is a low-power (60-W peak) pulsed radar operating at $9.42 \mathrm{GHz}$ (Fig. 1c). A parabolic-offset antenna, with a gain of 40 decibels-isotropic ( $\mathrm{dBi}$ ) and beamwidth of $1.9^{\circ}$, is used to minimize the effects of secondary beams and ground clutter. This radar system is primarily dedicated to measurements within urban areas. The measurements were obtained continuously along the vertical direction, with a time resolution of $\sim 6 \mathrm{~s}$ and a range resolution of $22.5 \mathrm{~m}$, for heights ranging from 70 to $720 \mathrm{~m}$. The CURIE radar provides measurements of the first three Doppler moments.

WINDCUBE LIDAR PROFILER. The Windcube lidar profiler, from the company Leosphere, is a pulsed and coherent (heterodyne) lidar, emitting infrared (IR) radiation (at $1.5 \mu \mathrm{m}$ ). To provide a vertical profile of the three components of the wind, a Doppler beam swinging (DBS) mode is used, which consists of a scan sequence with the acquisition of five Doppler spectra in five different looking directions. Therefore, a complete cycle of five radial wind velocity measurements lasts $4 \mathrm{~s}$. One direction is vertical and four directions are $28^{\circ}$ off vertical in two orthogonal planes. The 3D wind field is reconstructed from the five measurements of the radial velocities. The range resolution is $20 \mathrm{~m}$, for heights ranging from 70 to $290 \mathrm{~m}$ (Westerhellweg et al. 2010).

Mode-S. Mode-S enhanced surveillance (EHS) observations are obtained using secondary surveillance radar (SSR) used for ATM. On request by a tracking and ranging (TAR) radar, each aircraft responds with information on heading, airspeed, and Mach number from the onboard computer, from which the atmospheric temperature and the horizontal wind vector can be extracted. In general, en-route radars have a full scan period of $20 \mathrm{~s}$, while the approach radar scans with a period of $4 \mathrm{~s}$. The coverage of such radars is limited by the curvature of the Earth. The recorded messages also contain information 
on the movement of the aircraft generated by the flight computer. The message is complemented with information on the position and ground track from the tracking radar.

The horizontal wind vector at the location of an aircraft can be derived from its ground path, airspeed, and heading. A magnetic declination conversion is necessary to obtain true headings, because the magnetic heading values are downlinked. Furthermore, it appears that each individual aircraft has specific characteristics. Therefore, an additional aircraft and time-dependent correction for heading and airspeed needs to be applied (de Haan 2011). These corrections are based on statistical comparison with an NWP model over a long time period (de Haan 2013). The derived observations are called Mode-S EHS. When direct meteorological information is available, the observation is called Mode-S MRAR (meteorological routine air report; Strajnar et al. 2015). Both observation types have proven to be beneficial for short-term NWP models (de Haan and Stoffelen 2012; Strajnar et al. 2015).

\section{WIND VECTOR AND TURBULENCE IN- TENSITY RETRIEVAL TECHNIQUES AND} THEIR VALIDATION. Wind vector retrievals. With a lidar or radar, the line-of-sight velocity $V_{r}$ is measured using the Doppler-induced frequency shift on the backscattered signal and is expressed by (e.g., Doviak and Zrnić 1993)

$$
V_{r}=u \cos \theta \sin \varphi+v \cos \theta \cos \varphi+w \sin \theta
$$

where $\theta$ is the elevation angle, $\varphi$ is the azimuth angle, and $(u, v, w)$ are the wind components in a Cartesian coordinate system. Consequently, wind vectors are reconstructed by model-based parameter estimation. For example, the volume velocity processing (VVP) method can be applied to obtain wind vectors (Krishnamurthy et al. 2013; Kongara et al. 2012). With the VVP method, a linear wind model is used for each analysis volume (e.g., Doviak and Zrnić 1993). The accuracy of the retrieved wind vectors depends on the number of measurement samples within an analysis volume and the set of the fitted parameters. More samples will give a higher accuracy to the 10-min -averaged wind speeds. Too many fitting parameters with insufficient samples can lead to unstable results. When these parameters are properly chosen, good validation results can be found, for example, an accuracy of $0.06 \mathrm{~m} \mathrm{~s}^{-1}$ at 1.6-km range (Wagner and Courtney 2014) for a lidar system. For the radar, Eq. (1) also applies, but more challenges in the wind vector technique retrieval arise because of issues related to the radar measurement principle, such as 1) rain/cloud drops not being perfect tracers of the air motion and 2) data gaps due to insufficient reflection and/or data quality issues (Oude Nijhuis et al. 2016b). From a comparison of different retrieval techniques, it is found that a four-dimensional variational analysis (4D-Var) wind vector retrieval technique, based on an optimal estimation procedure, is most optimal for a single scanning Doppler radar for the retrieval of wind vectors, in particular at large distance from the radar location (Oude Nijhuis et al. 2014).

Turbulence intensity retrieval techniques. EDR, which is used as an indicator for turbulence intensity in aviation, originates from atmospheric turbulence studies (e.g., Pope 2000). The EDR is a measure for the viscous dissipation of turbulent kinetic energy (TKE), which is transferred from large scales to small scales within the inertial subrange via eddies. It is derived from the Navier-Stokes equations, in terms of the ensemble average of combinations of derivatives of the fluid velocities and the kinematic viscosity. As a consequence of Kolmogorov's similarity hypotheses that are valid for locally homogeneous and isotropic turbulence, the turbulent energy spectrum $E(\kappa)$ $\left(\mathrm{m}^{3} \mathrm{~s}^{-2}\right)$ of three-dimensional wind velocities in the inertial subrange is partitioned among the eddies in a universal form (Kolmogorov 1941; Sutton 1953; Pope 2000):

$$
E(\kappa)=C \varepsilon^{2 / 3} \kappa^{-5 / 3},
$$

where $\kappa=2 \pi / \lambda\left(\mathrm{m}^{-1}\right)$ is the wavenumber with wavelength $\lambda(\mathrm{m}), \varepsilon\left(\mathrm{m}^{2} \mathrm{~s}^{-3}\right)$ is the energy dissipation rate, and $C$ is a universal Kolmogorov constant that is determined from experiments (Sreenivasan 1995).

Next to Eq. (2), there exist one-dimensional turbulence energy spectra, and also second- and third-order structure functions, having different, but analytically related, universal constants (e.g., Pope 2000), which form the theoretical basis for EDR retrieval techniques. Integration of the turbulent energy spectrum leads to an analytical relation that is used to estimate an EDR value, based on the variance of velocities, for example, from Doppler lidar/radar measurements (Brewster and Zrnić 1986; Yanovsky et al. 2005; O'Connor et al. 2010; Bouniol et al. 2004). Other EDR retrieval techniques rely on processing of the power spectrum of velocities or structure functions of velocities (Siebert et al. 2006; Frehlich et al. 1998; Pope 2000). EDR retrieval techniques can also 
be applied in the temporal domain by using Taylor's hypothesis of "frozen" turbulence (Taylor 1938), allowing for the substitution

$$
t=s / U_{0}
$$

where $t$ is time, $s$ is distance, and $U_{0}$ is the mean flow speed. This substitution is, for example, used for in situ sensors, where the wind field fluctuation measurements are advected with the mean flow speed $U_{0}$. This substitution is an approximation and is only valid in the case when the turbulent circulations are smaller than the advection, and when the magnitudes of the turbulent velocities are small in comparison to $U_{0}$ (Monin and Yaglom 1975, p. 361).

Application to measurements. There are numerous manners in which an EDR value can be obtained from measurements. In the literature there is, however, no consensus on an optimal or standard EDR retrieval technique, and more research is required regarding this topic. Within the UFO project, different EDR retrieval techniques have been applied for each measurement system, as a technique is more favorable for technical reasons and/or it is the preference of a research group. Here an overview is given of the EDR retrieval techniques that were applied to the clear-air profiling radar, the scanning lidar, and the X-band scanning radar.

For the clear-air profiling radar (CURIE radar), the radar Doppler spectral widths have been used to estimate EDR values. The CURIE radar is used for turbulence measurements in clear-air conditions only, because it is difficult to retrieve the spectral broadening of the clear air in rainy conditions. The rain echoes for this type of radar are very strong and have large Doppler spectral widths. The distribution of the fall speeds of the hydrometeors makes the detection of the clear-air echoes very difficult.

The measured radar Doppler spectral width $s_{r}$ can be written as a sum over independent terms (Frisch and Clifford 1974; Gossard et al. 1998; White et al. 1999; Jacoby-Koaly et al. 2002):

$$
\sigma_{r}^{2}=\sigma_{t}^{2}+\sigma_{b}^{2}+\cdots
$$

where $s_{t}$ is the turbulence Doppler spectral width and $s_{b}$ is the antenna beam broadening. Additional terms can exist in Eq. (4), due to wind shear broadening or nonturbulence fluctuations, for example, gravity waves (e.g., Nastrom 1997; Nastrom and Eaton 1997; Wilson 2004). Such additional terms are small under most circumstances for small beamwidths and are neglected. Consequently, the turbulence term can be estimated as (Frisch and Clifford 1974; Gossard et al. 1998; White et al. 1999; Jacoby-Koaly et al. 2002)

$$
\sigma_{t}^{2}=\sigma_{r}^{2}-\sigma_{b}^{2}
$$

A standard beam broadening correction has been applied from White et al. (1999), and consequently, the EDR value is estimated as

$$
\varepsilon=\sigma_{t}^{3}\left(\frac{4 \pi}{C_{1}}\right)^{3 / 2} I^{-1},
$$

where $I$ is an integral depending on the mean horizontal wind and on the dimensions of the radar volume, and $C_{1}$ is a constant related to $C$ (White et al. 1999).

For the scanning Doppler lidar and scanning Doppler radar, EDR values are estimated from the standard deviation of a series of Doppler velocities from a single line of sight (e.g., Oude Nijhuis et al. 2016a):

$$
\varepsilon=\left[\frac{3}{2} C_{\mathrm{LOS}}\left(\kappa_{\mathrm{TS}}^{-2 / 3}-\kappa_{S}^{-2 / 3}\right)\right]^{-3 / 2} \sigma_{t}^{3},
$$

where $s_{t}$ is the standard deviation of line-of-sight velocities. Equation (7) is obtained from integration of a similar expression as Eq. (2), with only the difference of having a different Kolmogorov constant $C_{\text {LOS }}$, which is relevant for line-of-sight velocities and the radar/lidar antenna direction. The wavenumbers $\kappa_{S}$ and $\kappa_{\mathrm{TS}}$ are the limits of the part of the turbulent energy spectrum that is being sampled. They are related to the sampling scale $\lambda_{S}$, via $\kappa_{S}=2 \pi / \lambda_{S}$, and the total sampling scale $\lambda_{\mathrm{TS}}$, via $\kappa_{\mathrm{TS}}=2 \pi / \lambda_{\mathrm{TS}}$.

By using a large totaling sampling scale, approximately $2 \mathrm{~km}$ in this study, and using a low-elevation radar looking angle, the resulting EDR values are independent of an accurate estimation of the rain drop size distribution (DSD). By using a low-elevation radar looking angle, the measured variance in raindrop fall speeds is minimized because the variance in raindrop fall speeds is maximal in the vertical direction and zero in the horizontal directions. By using a total sampling scale that is much larger than $30 \mathrm{~m}$, the influence of raindrop inertia can be neglected [details in Oude Nijhuis et al. (2016b)]. It is further assumed that the measurement samples are in the inertial subrange and Eq. (2) is applicable. Because of this assumption, the resulting EDR values can be biased because of more localized weather phenomena, such as building-induced turbulence.

Validation of a clear-air radar-based EDR retrieval technique via simulations. The retrieval of EDR values with 
a clear-air profiling X-band radar is new. Therefore, the EDR retrieval technique is validated for this instrument with LESs and a clear-air radar signal simulator. The main question to answer with these simulations is whether the observations are unbiased, and thus reliable, for a variety of different EDR values and atmospheric stratification levels. In addition, the simulations can give some confidence to assert that the turbulence intensity values are derived from atmospheric motions and not from radar noise signals.

A simulator of radar signals, which are scattered by tropospheric turbulence in clear air, has been developed at Université catholique de Louvain (UCL). It is based on LES modeling of the turbulent troposphere with stable stratification. The LES provides realistic $4 \mathrm{D}$ fields of velocity, pressure, temperature, and humidity in homogeneous isotropic turbulence, for a given value of EDR and stratification (Brunt-Väisälä frequency). Those fields are then used to simulate the radar signal backscattering. The LES model was adapted from De Visscher et al. (2013) to introduce water vapor. It was run for a combination of four values of EDR and three stratification levels. The resolution of the model in space and time is $0.78 \mathrm{~m}$ and $1 \mathrm{~s}$, respectively. In this article, the results obtained with the simulator are validated against LES input values of EDR for clear-air conditions only.

The model for calculation of radar signal backscattering in clear air extends the method proposed by Muschinski et al. (1999) from S-band to X-band radars, as explained hereafter. Backscattering of electromagnetic waves occurs on clear-air refractive index inhomogeneities with a scale equal to the Bragg wavelength (e.g., Doviak and Zrnic 1993), corresponding to half the radar wavelength, which is $1.6 \mathrm{~cm}$ for the CURIE radar. Muschinski et al. use a parameterized model for the calculation of the scattered signal received by the radar (scattering integral). The temporal changes of phase and amplitude of the signal are based on the use of an LES snapshot, advected by local wind velocity, and with the assumption of linear changes of all the LES parameters between two successive snapshots. The amplitude and the phase of the coherent complex signal received by the radar are calculated as a function of the local refractive index structure constant of the atmosphere $C_{n}^{2}$ and the velocity vector field obtained from LES data (Pereira et al. 2014; Kovalev et al. 2016).

The three main hypotheses of the Muschinski model are that 1) the LES subfilter turbulence obeys Kolmogorov scaling (inertial subrange) at the Bragg scale, 2) the contributions of the phases of the LES grid points to the scattering integral are statistically independent, and 3) the radar cell contains a large number of LES points to ensure sufficiently sampled statistics. For the parameters of the CURIE radar and the LES resolution of $0.78 \mathrm{~m}$, the two last hypotheses are fulfilled: the size of the LES cells $(0.780 \mathrm{~m})$ is much larger than the Bragg wavelength $(1.6 \mathrm{~cm})$, and the size of the radar cell in range is about $23 \mathrm{~m}$ and is much larger than the LES cell. With regard to the first assumption, it is expected that for the X-band radar the Bragg scale lies in the dissipative range or in the transition zone from the inertial subrange to the viscous dissipative range for most of the combinations of LES parameters.

The UCL model includes the exponential decrease of the refractive index spectrum in the calculation of the backscattered signal to account for the attenuation of the spectrum level in the dissipation range:

$$
\Phi_{n}\left(k_{B}\right)=0.033 C_{n}^{2} k_{B}^{-11 / 3} e^{-k_{B}^{2} / k_{m}^{2}},
$$

where $k_{B}$ is the Bragg wavenumber and $k_{m}=5.92 / l_{0}$ (Tatarski 1971), where $l_{0}$ is the inner scale of turbulence. It corresponds to the smallest inhomogeneities in the velocity field and is calculated using the following expression (Hill and Clifford 1978):

$$
k_{m}=0.8\left(\frac{\mathrm{EDR}}{v^{3}}\right)^{1 / 4},
$$

where $v$ is the kinematic viscosity of the air, and EDR is derived from the LES itself.

The simulated radar-based estimation of the EDR uses the calculation of the first and second moments of the scattered signal Doppler spectrum above a given threshold, estimated for the selected spectrum estimator and window (Kovalev et al. 2016). A minimum "peak to threshold" of $14 \mathrm{~dB}$ is used in the simulator; it gives the EDR estimation accuracy of the first line of Table 2 (inertial subrange). For further comparison between inertial and dissipative subrange hypotheses, all the parameters are kept constant, including the threshold level. Applying the exponential decrease reduces the refractive index spectrum $\Phi_{n}$ with respect to the inertial subrange case
TABLE 2. Accuracy of the EDR estimation defined as mean $\left(E D R_{\text {radar }}\right) / E D R_{\text {LEs_input }}$ Inertial subrange and dissipative range rows correspond to the use of refractive index spectrum without and with exponential decrease, respectively.

\begin{tabular}{|lllll|}
\hline $\mathbf{E D R}^{1 / 3}\left(\mathbf{m}^{2 / 3} \mathbf{s}^{-1}\right)$ & $\mathbf{0 . 2 1 5}$ & $\mathbf{0 . 1 5}$ & $\mathbf{0 . 0 7 9 3}$ & $\mathbf{0 . 0 2 1 5}$ \\
\hline Inertial subrange & 1.08 & 0.98 & 0.997 & 0.22 \\
\hline Dissipative range & 0.81 & 0.73 & 0.25 & 0 \\
\hline
\end{tabular}


and the peak-to-threshold value accordingly. So, the error in the estimation of the EDR increases. In this simulator, no noise floor is taken into account. For a real radar, the noise floor will define this threshold.

To verify the accuracy of the radar backscattering simulator, EDR is estimated from the Doppler spectrum for the various LES cases and compared to the EDR that was used as input for the LES. In total, $1 \mathrm{~h}$ of scattered signal time series is generated with a radar configuration corresponding to the CURIE radar. It results in 610 Doppler spectra calculated from consecutive trains of 4,096 pulses obtained with the radar simulator. Each 10 consecutive Doppler spectra are averaged and 61 samples of EDR are retrieved using Eqs. (5) and (6).

In Fig. 2a, the four different values of $\operatorname{EDR}^{1 / 3}$ used as input for the LES are plotted against the values of $\mathrm{EDR}^{1 / 3}$ retrieved from the radar simulator, assuming that the Bragg wavelength lies in the inertial subrange [without the exponential factor in Eq. (8)]. The simulated data show that the method [Eqs. (5) and (6)] accurately retrieves the EDR values from the Doppler spectrum width. Some underestimation occurs for the LES case with the lowest level of EDR. For that case, the width of the Doppler spectrum becomes comparable to the antenna beam broadening width from Eq. (5), which is subtracted from the Doppler spectrum width before the calculation of the EDR.

In a second simulation (Fig. 2b), the hypothesis of the Bragg wavelength being in the inertial subrange is

(a)

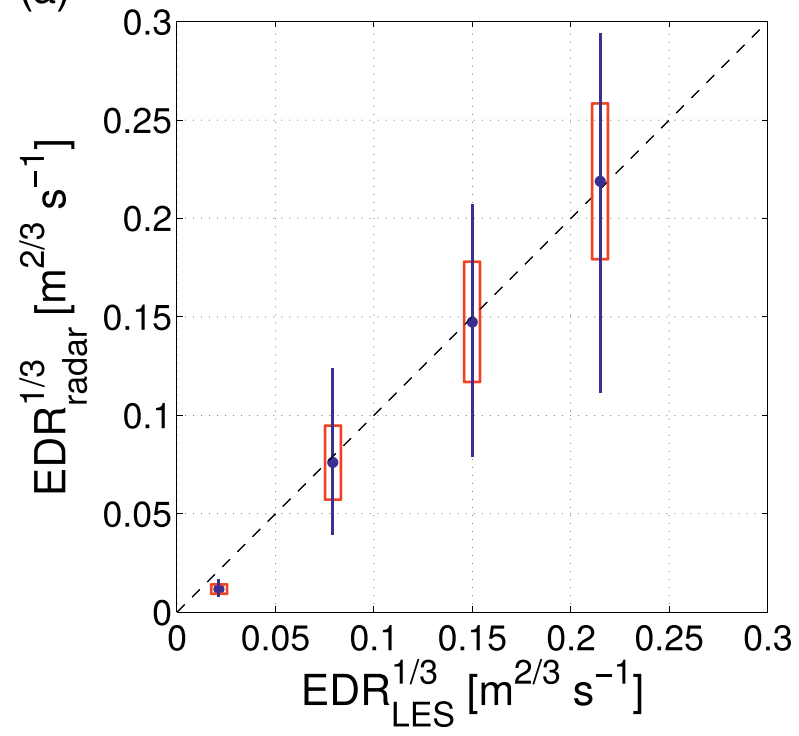

released. The full spectrum of the refractive index is used [Eq. (8)], including the dissipative range. When the Bragg wavelength is in the dissipative region, the peak-to-threshold value decreases, while keeping all other simulation parameters constant. The Doppler spectrum width seen above the threshold is then reduced. This leads to an underestimation of EDR. Figure $2 \mathrm{~b}$ demonstrates this underestimation of EDR when it is retrieved from the simulated Doppler spectrum.

The results for the LES cases with the weakest turbulence show that there is no appreciable scattering for the 1.6- $\mathrm{cm}$ Bragg wavelength because it belongs to the dissipative range. Table 2 summarizes the estimation accuracy in linear scale. The simulator thus confirms the difficulties for a clear-air X-band radar to retrieve accurate EDR values, in particular for EDR values smaller than $0.15 \mathrm{~m}^{2 / 3} \mathrm{~s}^{-1}$. Further, it is demonstrated that the sensitivity of this EDR retrieval technique for clear-air X-band radar can be estimated by using the UCL model.

\section{COMPARISON AND COMBINATION OF DIFFERENT SOURCES. In this section, retrieved} wind vectors and turbulence intensities are demonstrated to show the benefit of the new sensors. Both vertical profiles and scans of wind vectors were retrieved with the UFO wind hazard measurement systems in the TMA during trials at Toulouse-Blagnac Airport in 2014. In addition, in situ measurements

(b)

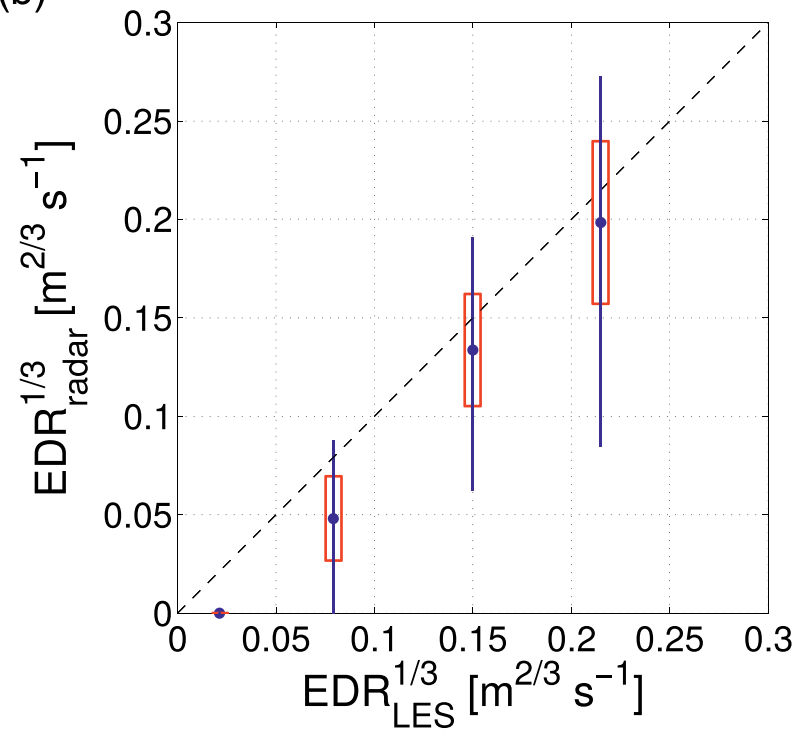

FIG. 2. (a) EDR estimated from simulated clear-air profiling radar backscattering vs LES EDR input value, without the exponential decrease in the refractive index spectrum. (b) EDR estimated from simulated clearair profiling radar backscattering vs LES EDR input value, with the exponential decrease. Blue lines depict the range between the minimum and maximum values of the estimated EDR. Blue dots are the mean values of the estimations for each case. Red boxes display the standard deviation of radar simulator estimates of EDR values. 
(a)

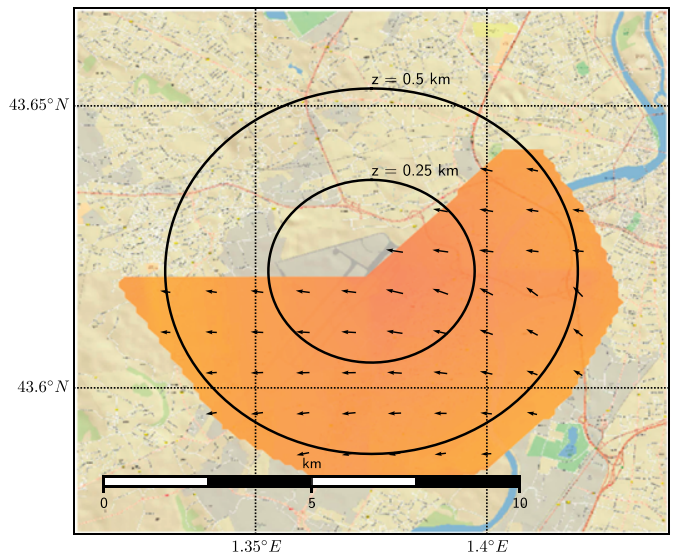

(b)

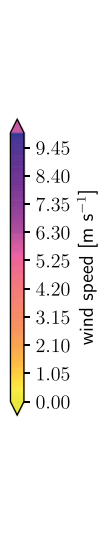

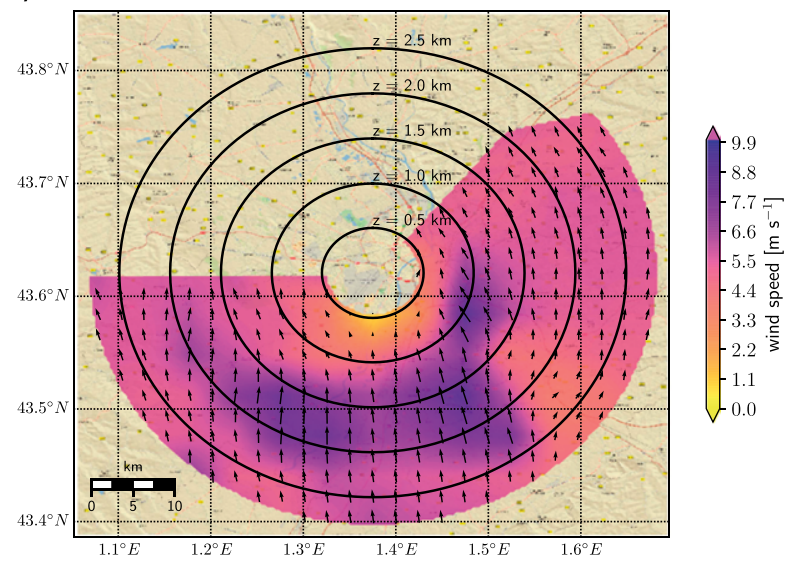

FIG. 3. Retrieved wind vectors during the Toulouse trials at 1412 UTC 24 Apr 2014 from (a) the scanning Doppler lidar and (b) the scanning Doppler radar. In the background the wind speed is plotted in color contours, and the wind direction is shown with arrows on top. The altitudes of the measurements are shown with circles in the background.

from weather sensors and from a research aircraft from Technische Universität Braunschweig have been used as reference measurements to validate the results. Specific details on the setup of measurement systems can be found in Barbaresco et al. (2015).

Wind vectors. In Fig. 3 the result of wind vector scans is shown, where both the scanning lidar and the scanning radar are working simultaneously to get a display of wind speed and wind direction in the vicinity of the airport. Note that the altitudes of the measurements are shown with circles in the background. In Fig. 3a retrieved wind vectors are shown for lidar in the ABL. Close to the surface, where the lidar instrument was measuring, the wind field is rather homogeneous and no strong winds were measured. As there was light rain during these measurements, the lidar was not able to measure beyond $5 \mathrm{~km}$ due to attenuation. The observation of wind vectors and turbulence beyond $5 \mathrm{~km}$ were obtained from the scanning X-band radar, which is shown in Fig. $3 \mathrm{~b}$. At the higher altitudes $(>500 \mathrm{~m})$, stronger wind was measured with values of up 8-9 $\mathrm{m} \mathrm{s}^{-1}$. These wind maps help to improve the awareness of hazardous wind at the airport.

The bias and standard deviation (STD) of the wind speed measurements with UFO wind hazard measurement systems have been estimated by a comparison to reference sensors and are given in Table 3 . The dataset used consists of one month of data from April to May 2014. The lidar wind profiler has been chosen as a reference sensor since it has the highest data availability and is considered the most accurate for upper-air wind measurements. This reference wind sensor was also calibrated against a certified met mast by an independent certification entity before the campaign.

One-minute-averaged glide path wind speeds from the scanning Doppler lidar have been compared to research aircraft measurements over four flights showing a low bias of $0.57 \mathrm{~m} \mathrm{~s}^{-1}$ and a low STD of $0.51 \mathrm{~m} \mathrm{~s}^{-1}$. These numbers demonstrate that wind speeds can be obtained in the glide path reliably. Ten-minute-averaged vertical wind speeds from the scanning lidar have been compared to a vertical lidar profiler located $5 \mathrm{~km}$ away at altitudes of 80,150 , and $200 \mathrm{~m}$. The 10 -min average is commonly used in aviation meteorology. The estimated bias of $0.11 \mathrm{~m} \mathrm{~s}^{-1}$ is low, but a rather high STD of $1.63 \mathrm{~m} \mathrm{~s}^{-1}$ is estimated, which is likely due to the low update rate of $5 \mathrm{~min}$ for the scanning lidar volume wind measurements. Within $10 \mathrm{~min}$, only two sequences were performed in this configuration. The radial Doppler velocities of
TABLE 3. Absolute value of bias and standard deviation $\sigma$ for wind speed measurements for UFO wind hazard measurement systems. For the scanning radar, Doppler velocities are used for the estimation of bias and $\sigma$.

\begin{tabular}{|l|l|c|c|}
\hline Measurement system & Reference & Bias $\left(\mathbf{m ~ s}^{-1}\right)$ & $\boldsymbol{\sigma}\left(\mathbf{m ~ s}^{-1}\right)$ \\
\hline Scanning lidar (glide path) & Research aircraft & 0.57 & $0.5 \mathrm{I}$ \\
\hline Scanning lidar (volume) & Lidar profiler & 0.11 & 1.63 \\
\hline Scanning radar & Scanning lidar & 0.8 & 1.18 \\
\hline Mode-S EHS & Lidar profiler & 1.82 & 2.49 \\
\hline Mode-S MRAR & Lidar profiler & 0.19 & 0.58 \\
\hline
\end{tabular}



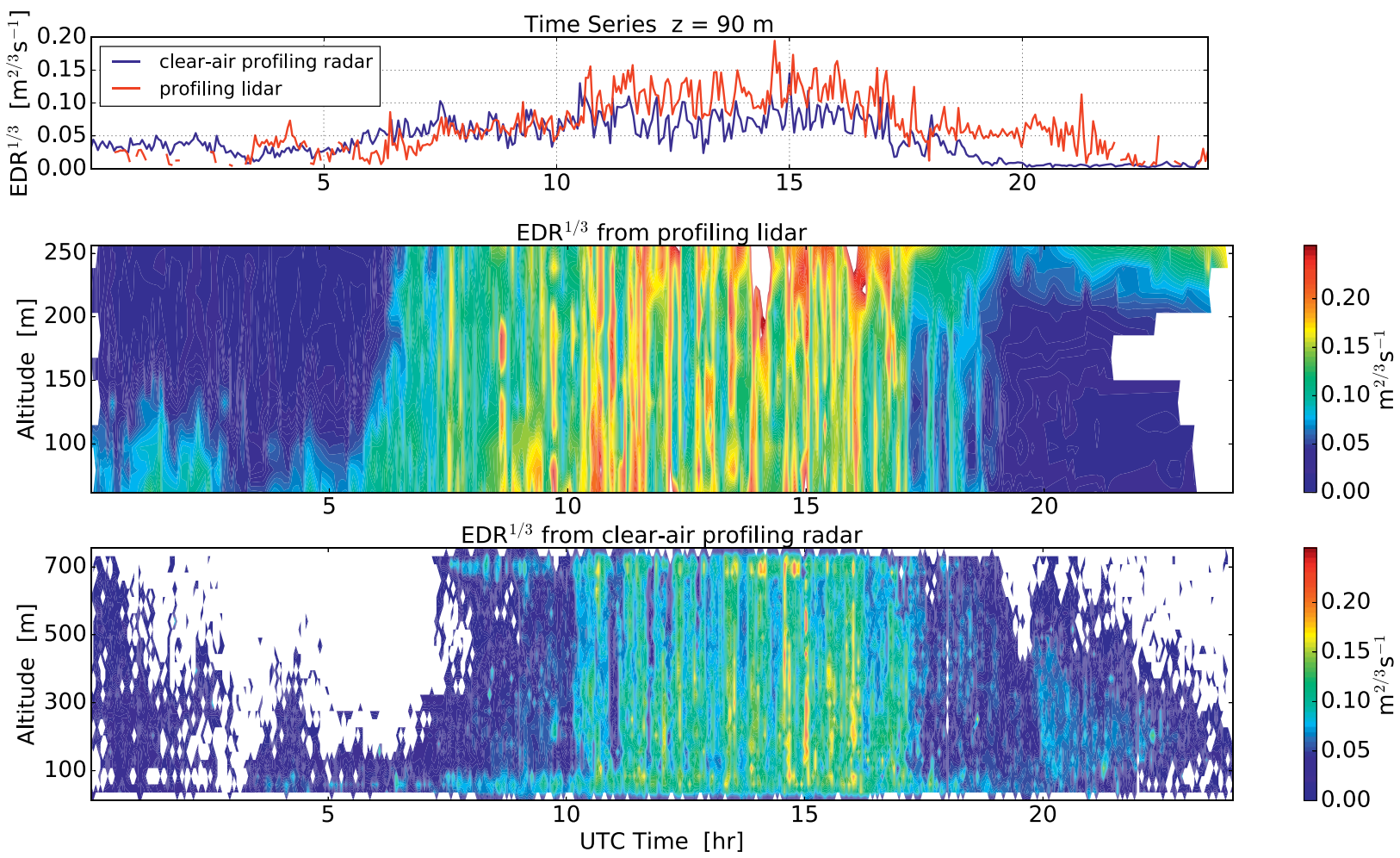

FIG. 4. (top) Time series of EDR ${ }^{1 / 3}$ from the Leosphere Doppler lidar profiler (red) and the CURIE radar (blue) during a day, showing the diurnal cycle of turbulence intensity at Trappes on 8 Aug 2013 at 90 m. (middle) Time-height cross section of EDR ${ }^{1 / 3}$ from the Doppler lidar profiler, and (bottom) time-height cross section of EDR ${ }^{1 / 3}$ from the CURIE radar.

the scanning X-band radar and the scanning Doppler lidar have been compared for four days during the Toulouse trials. The bias of $0.8 \mathrm{~m} \mathrm{~s}^{-1}$ and an STD of $1.18 \mathrm{~m} \mathrm{~s}^{-1}$ for the scanning radar show a fairly good agreement.

The bias and STD of Mode-S downlinked wind speeds have also been compared to the Windcube profiling lidar that provided measurements in the glide path. The wind speeds retrieved by the Mode-S EHS method are not very accurate with respect to the other UFO wind hazard measurement systems and show a rather crude bias and STD. The more direct measurements from Mode-S MRAR provide much lower bias and STD results of 0.19 and $0.58 \mathrm{~m} \mathrm{~s}^{-1}$, respectively, which is comparable to the other UFO remote wind hazard measurement systems.

EDR from radarlidar profilers. In addition to the Toulouse trials, a measurement campaign at Trappes, France, was carried out for the comparison of EDR values between the CURIE X-band profiling radar and the Windcube profiling lidar. Synchronous time series of EDR values measured by radar and lidar profilers are shown in Fig. 4. Both instruments revealed the diurnal cycle of turbulence. During the day, convection occurs and turbulence is fully developed, which can be seen in the obtained profiles of refractive index from the ground level to the top of the ABL. The estimated EDR values show a reasonable agreement, at least for the cases when convection occurs (i.e., before 1800 local time), with values in the range $0.01 \leq \mathrm{EDR}^{1 / 3} \leq 0.22 \mathrm{~m}^{2 / 3} \mathrm{~s}^{-1}$ (or alternatively $10^{-6} \leq \mathrm{EDR} \leq 10^{-2} \mathrm{~m}^{2} \mathrm{~s}^{-3}$ ). Such EDR values indicate light to moderate turbulence levels (e.g., ICAO 2016). Both of the profilers-the low-power X-band radar and the Windcube lidar-are thus able to detect turbulence and to measure the evolution of turbulence intensity in the lower ABL during the day.

Figure 5 shows typical space-time distributions of turbulence intensity as observed by the CURIE radar during the Toulouse-Blagnac Airport trials (9 April 2014). The top panel shows the refractive index of air due to turbulence $\left(C_{n}^{2}\right)$, the middle panel shows the vertical velocity $w$, and the bottom panel shows the estimated EDR. For this particular day, the convection appears to be much weaker than for the Trappes study case. Despite this difference, EDR values are found to be quite similar at both sites, that is, $0.01 \leq \mathrm{EDR}^{1 / 3} \leq 0.2 \mathrm{~m}^{2 / 3} \mathrm{~s}^{-1}$. These figures illustrate a typical daily cycle of turbulence intensity that was observed during most of the days of the Toulouse 


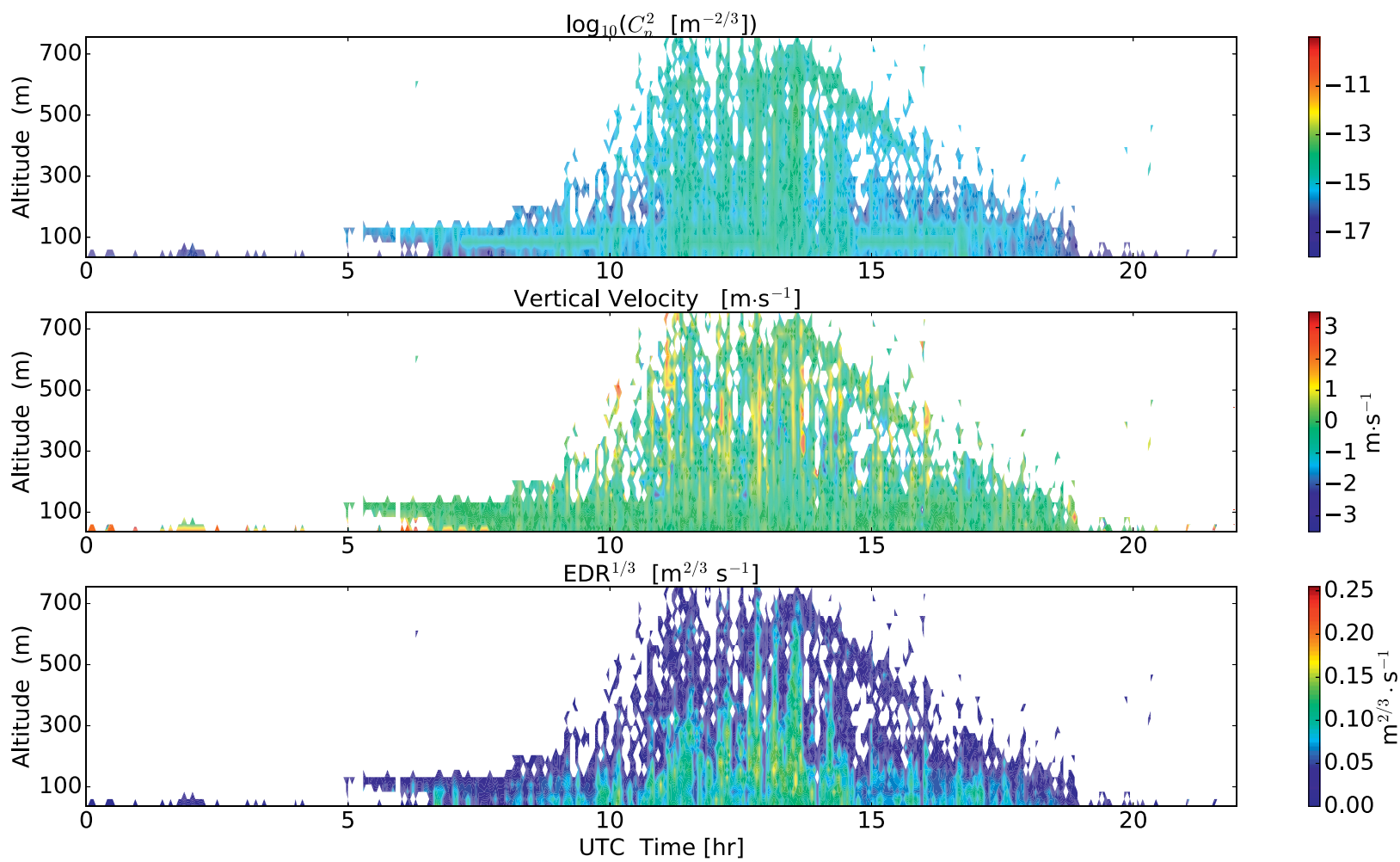

FIG. 5. Diurnal cycle of turbulence intensity and vertical velocity observed by the CURIE radar at ToulouseBlagnac Airport on 9 Apr 2014: (top) $C_{n}^{2}$, (middle) vertical velocity w, and (bottom) EDR ${ }^{1 / 3}$.

trial, except during rain, and thus illustrate the capability of the X-band profiling radar to provide useful wind and turbulence information at airports. To our knowledge, these figures demonstrate the capability for turbulence measurements with a profiling $\mathrm{X}$-band radar system during clear-air conditions for the first time.

Existing algorithms for retrieving EDR have thus been applied to a clear-air X-band radar and a Doppler lidar and have been validated through simulations. Applied to the datasets of the Toulouse-Blagnac Airport, both sensors are able to provide the profiles of EDR in the boundary layer and to observe the mixing layer, including its development from sunrise to sunset. The orders of magnitude of EDR obtained are similar. The remaining differences in the retrieved EDR values between the two sensors might come from the differences in the measurement principle of each sensor. From the analysis of these study cases, it is not possible to assert an ultimate accuracy of the retrieved EDR values. Nevertheless, it is shown that the retrieved EDR values are qualitatively valid. Further quantitative analysis for a large dataset is then needed before these systems can be deployed operationally.

EDR from scanning radar and scanning lidar. Next to maps of wind, EDR intensity maps can help to enhance the awareness of hazards due to turbulence (e.g., Chan 2011). For the scanning Doppler lidar and the scanning Doppler radar, the variance of measured Doppler mean velocities in the line of sight is used to estimate EDR [Eq. (7)]. The resulting EDR maps are shown in Fig. 6. Please note that the altitudes of these measurements are shown with circles in the background. An example of a lidar EDR map is shown in Fig. $6 \mathrm{a}$. In the vicinity of the airport $(<5 \mathrm{~km})$ and low altitudes $(<500 \mathrm{~m})$, low to moderate turbulence levels are found in this case. With the scanning X-band radar, the measurements are complemented, which is shown in Fig. 6b. Some small peak EDR values observed by the radar likely indicate wake turbulence from buildings, or aircraft wake turbulence, or other small-scale turbulence phenomena. In addition to that, there are large sections with high EDR values, in this case predominantly in the easterly direction with regard to the airport. The scanning UFO sensors can thus also improve the awareness of hazards due to turbulence, where the scanning X-band radar complements the scanning lidar measurements that are attenuated due to the raindrops.

Although almost identical EDR retrieval techniques have been applied and validated with in situ measurements (e.g., O'Connor et al. 2010; Siebert et al. 2006), it is, nevertheless, desired in future operational 

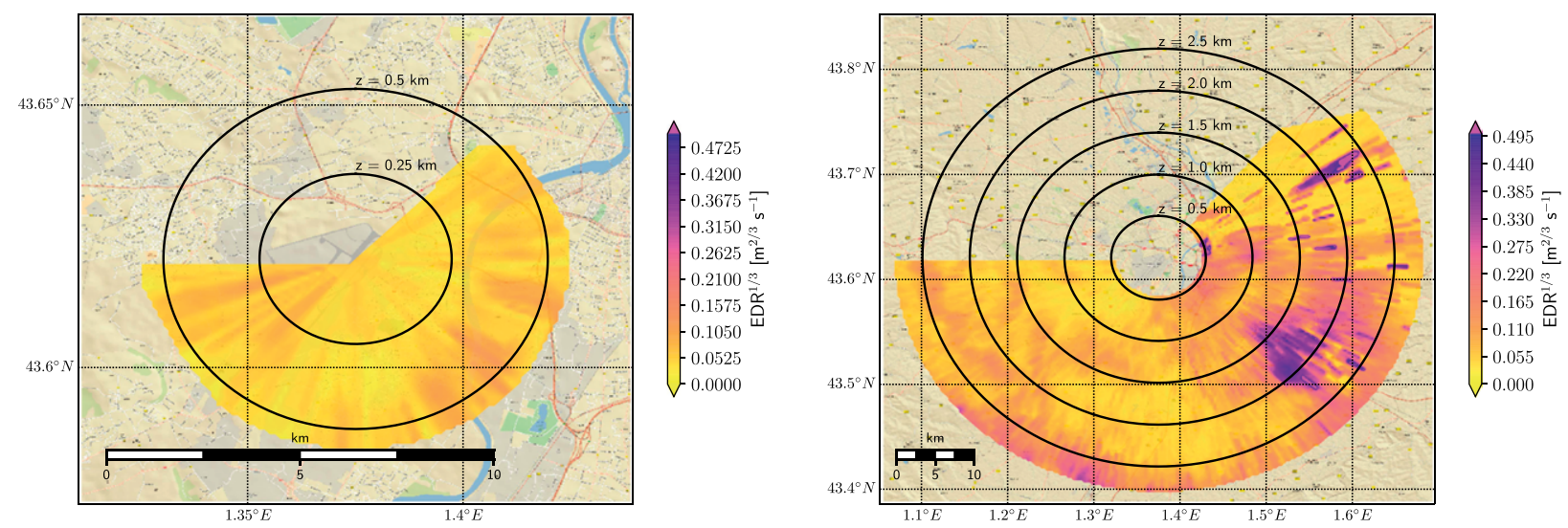

Fig. 6. Retrieved EDR values during the Toulouse trials at 1412 UTC 24 Apr 2014 from (a) the scanning Doppler lidar and (b) the scanning Doppler radar. EDR values are shown in color contours. The altitudes of the measurements are shown with circles in the background.

applications that the retrieved EDR values from the new types of instruments (scanning lidar and scanning radars) will be further validated and compared to in situ EDR measurements.

Proposed combination of UFO wind hazard measurement systems. The performance levels of the scanning radar and scanning lidar have been studied for different ranges (distances to the instruments) via simulations and data analysis to identify under which meteorological circumstances they can be used to retrieve wind vectors and EDR, and how they can work together. The performance is schematically plotted in Fig. 7 as a function of visibility and rainfall rate. The domains are shown where wind vectors and EDR can be retrieved for specified ranges. During the campaign measurements, the X-band radar

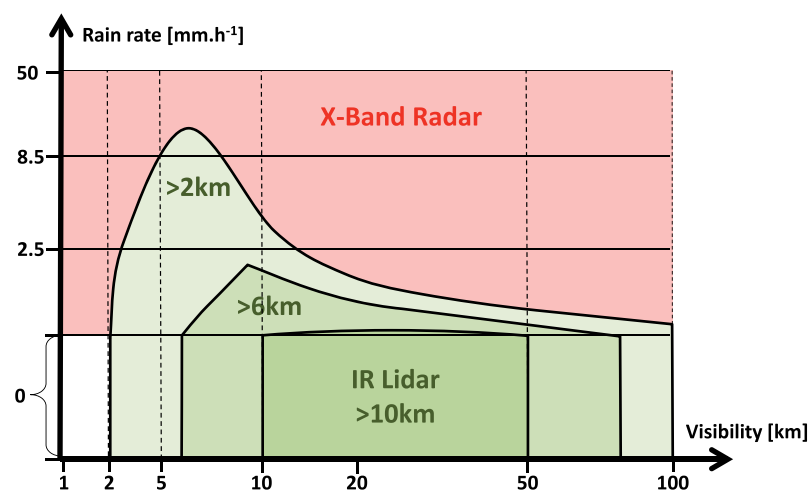

FIG. 7. Performance of the scanning lidar and scanning radar under different weather conditions. The availability of measurements from the Leosphere scanning lidar is plotted as a function of visibility and rain rate, for up to 2, 6, and $10 \mathrm{~km}$ in range with different green colors. The availability of radar measurements is displayed as the light red surface. could be used in all rainy conditions to retrieve EDR and wind vectors for the required range of $10 \mathrm{~km}$, and not during clear-air conditions. The lidar range performance is mainly driven by aerosol content, which can be expressed in terms of the meteorological visibility and the rainfall rate. As there is a direct link between visibility and atmospheric extinction, the lidar signal attenuation is approximately proportional to the visibility (Koschmieder 1925). This means that for clear-air conditions (visibility above $10 \mathrm{~km}$ and low extinction), the lidar measurement range exceeds $10 \mathrm{~km}$. When there is moderate extinction (low visibility/light rain), the lidar measurement range is reduced. During the Toulouse trials, the lidar maximum range was reduced from 9.5 to $6 \mathrm{~km}$ in light-rain conditions. In cases of heavy rain, the maximum range was significantly reduced further down to $2 \mathrm{~km}$. In Fig. 7, the domains where the scanning lidar can be used to estimate wind vectors and EDR are displayed, respectively, in light green ( $>2-\mathrm{km}$ range), green ( $>6-\mathrm{km}$ range), and dark green $(>10-\mathrm{km}$ range). More details with regard to these performance studies can be found in Barbaresco et al. (2015).

The studies on performance have confirmed that in cases of rainy weather the scanning X-band radar will be the instrument of choice, and the scanning lidar will be better used in clear-air conditions. The analyses of the data collected at the Toulouse trial have led to the following conclusions: 1) in clear-air conditions, the lidar measurements between 7 and $10 \mathrm{~km}$ are useful for about $50 \%$ of all measurement time, and 2) in case of light rain (up to $2.5 \mathrm{~mm} \mathrm{~h}^{-1}$ ), the lidar range can be reduced up to $36 \%$. Below $0.5 \mathrm{~mm} \mathrm{~h}^{-1}$, the range reduction is much smaller. For light rain, the scanning radar and lidar have a 
common area of measurements, which is up to the maximum range of the lidar for such cases $(\sim 6 \mathrm{~km})$. In the case of moderate and heavy rain, the lidar range is reduced by at least $80 \%$. Nevertheless, the lidar range can then be useful to complement the radar for measurements close to the location of the instruments, where the radar cannot measure because of a minimal measuring range. For the radar it can be concluded that 1) in clear air, the range is limited to only a few kilometer(s), and 2) in case of heavy rain, the range is limited by attenuation, but for rain intensities of up to $75 \mathrm{~mm} \mathrm{~h}^{-1}$ the maximum range is sufficient for the UFO measurement system objectives $(10 \mathrm{~km})$. At this site, the clear-air conditions correspond to $90 \%$ of the weather conditions, and conditions with rain rates above $1.1 \mathrm{~mm} \mathrm{~h}^{-1}$ correspond to $1 \%$.

With respect to NWP models, the future synergy of UFO wind hazard measurement systems is summarized in Fig. 8. The recommendations regarding these measurement systems are 1) complementarity of X-band electronic scanning radar (in rainy conditions) and the scanning lidar (in clear air) for fast and far-range monitoring at low altitudes (altitude $<500 \mathrm{~m}$, range $<10 \mathrm{~km}$ along the glide slope) and 2) complementarity with Mode-S EHS downlinks for wind at high altitudes (altitude $>500 \mathrm{~m}$ ) in all weather conditions and at low altitudes (altitude $>500 \mathrm{~m}$ ) in cases of foggy weather conditions and/or rainy conditions.

There remain some challenges regarding the combination of an X-band radar and a Doppler lidar. In the case of fog, both X-band radar and $1.5-\mu \mathrm{m}$ Doppler lidar will have a strong reduction of range. In such weather conditions (low visibility and no rain; see Fig. 8), external sources of information are required. Mode-S downlinks are recommended for such conditions, or the addition of other measurement systems, such as cloud radars $(35 / 95 \mathrm{GHz})$.

ASSIMILATION OF LIDAR DATA INTO NWP MODELS. To assess the value of the new UFO observations for short-range NWP model forecasts, OSEs are performed. The NWP model used here is HARMONIE [High Resolution Limited Area Model (HIRLAM)-Aire Limitée Adaptation Dynamique Développement International (ALADIN) Research on Mesoscale Operational NWP in Euromed] on a 1-km horizontal grid, with an hourly 3D-Var assimilation cycle. An OSE experiment consists of a reference run, without the new observations assimilated, and a run with the new observations assimilated. When more new observations are available, combinations of observing systems can be

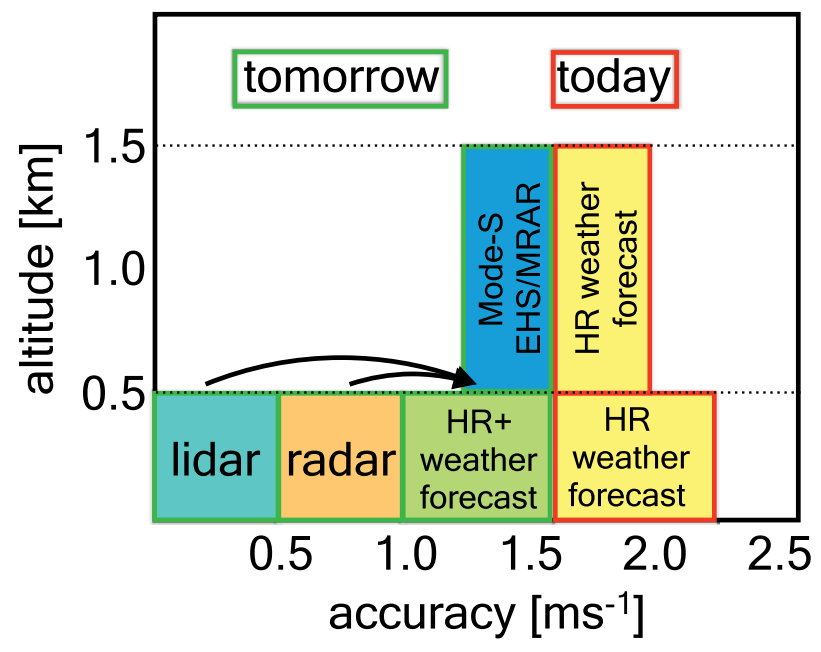

FIG. 8. Future synergy of UFO wind hazard measurement systems with regard to NWP models.

made. Table 4 shows the abbreviations and datasets used for the three experiments discussed here.

For wind forecast quality analysis, we have compared the wind forecast of the $u$ and $v$ components of the wind for all three experiments, with the profile of wind retrieved by the Windcube lidar profiler. The comparison is performed at 30-min intervals for all forecasts up to $+3 \mathrm{~h}$. Figure 9 shows the result of the comparison for the $u$ component. The comparison at $+00 \mathrm{~h}$ (i.e., analysis time) is biased toward the observation for experiment MRAR+VL (MRAR with vertical lidar), because these observations were used in the assimilation. At all other forecast times the observations are independent measurements of wind and can thus be used for verification. Clearly visible is the (short lived) positive impact of assimilating Windcube lidar profiler measurements. The other additional observation systems, when assimilated into the model, were not able to produce forecasts with similar performance as MRAR+VL. The positive impact is still present after $30 \mathrm{~min}$ to $1 \mathrm{~h}$, which is shown by a reduced STD when additional observations are assimilated. The impact is gradually disappearing with increasing forecast length, because the local spatial improvement introduced by the observation at analysis time is advected (and dissipated) by the forecast model. There is a smaller bias over almost

\begin{tabular}{|l|l|}
\hline \multicolumn{2}{|l|}{ TABLE 4. UFO observing system experiments. } \\
\hline Experiment & \\
\hline REF & Conventional observations \\
MRAR & + Mode-S MRAR \\
$M R A R+V L$ & + Mode-S MRAR \\
& + Windcube lidar profiler \\
\hline
\end{tabular}



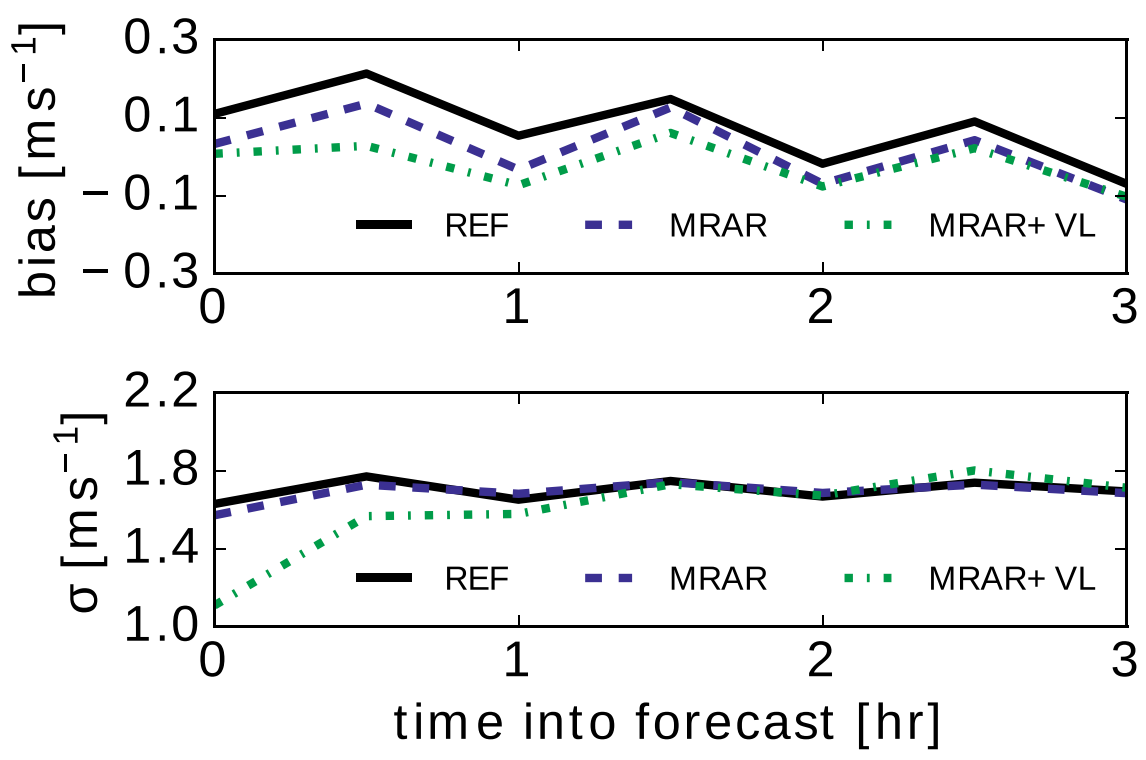

FIG. 9. Forecast statistics (bias and STD) for u component of the wind compared to observations from the Windcube lidar profiler for the three experiments in the period 5-20 May 2014.

the whole forecast range when MRAR observations are assimilated; additionally, when the Windcube lidar profiler information is used, the bias is further reduced. It is expected that when more upwind observations are available, the impact will be sustained longer in the forecast at the downwind location.

From Fig. 9 we saw that the impact is most pronounced in the first hours of the forecast. This is also illustrated in Fig. 10, where we plotted the wind vector field for four forecast times $(+0$ to
$+3 \mathrm{~h}$, columns), and two runs [reference (REF) and MRAR+VL, rows] valid at 2000 UTC 7 May 2014 $(+0$ h) until 0800 UTC 8 May $2014(+3 \mathrm{~h})$. The main difference between the two runs is the assimilation of the Windcube lidar wind information at ToulouseBlagnac Airport (denoted by the inverted triangle in the center of each panel). Note that there are wind lidar observations available south of Toulouse airport (triangles). The wind fields in the north and east are very similar for both runs. A region with low wind speeds (blue) is present in the southwest. A wind shift is approaching the airport from the north. There are (weak) westerly winds in the south at $+0 \mathrm{~h}$, while in the north there are northerly winds. Adding the Windcube lidar profile measurements results in a wind from the west and a sharp wind shift from northwest to west. The added adjustment is retained in the forecast for up to $+2 \mathrm{~h}$ and matches the lidar observation at all forecast times better than the forecast without the additional assimilated measurements.

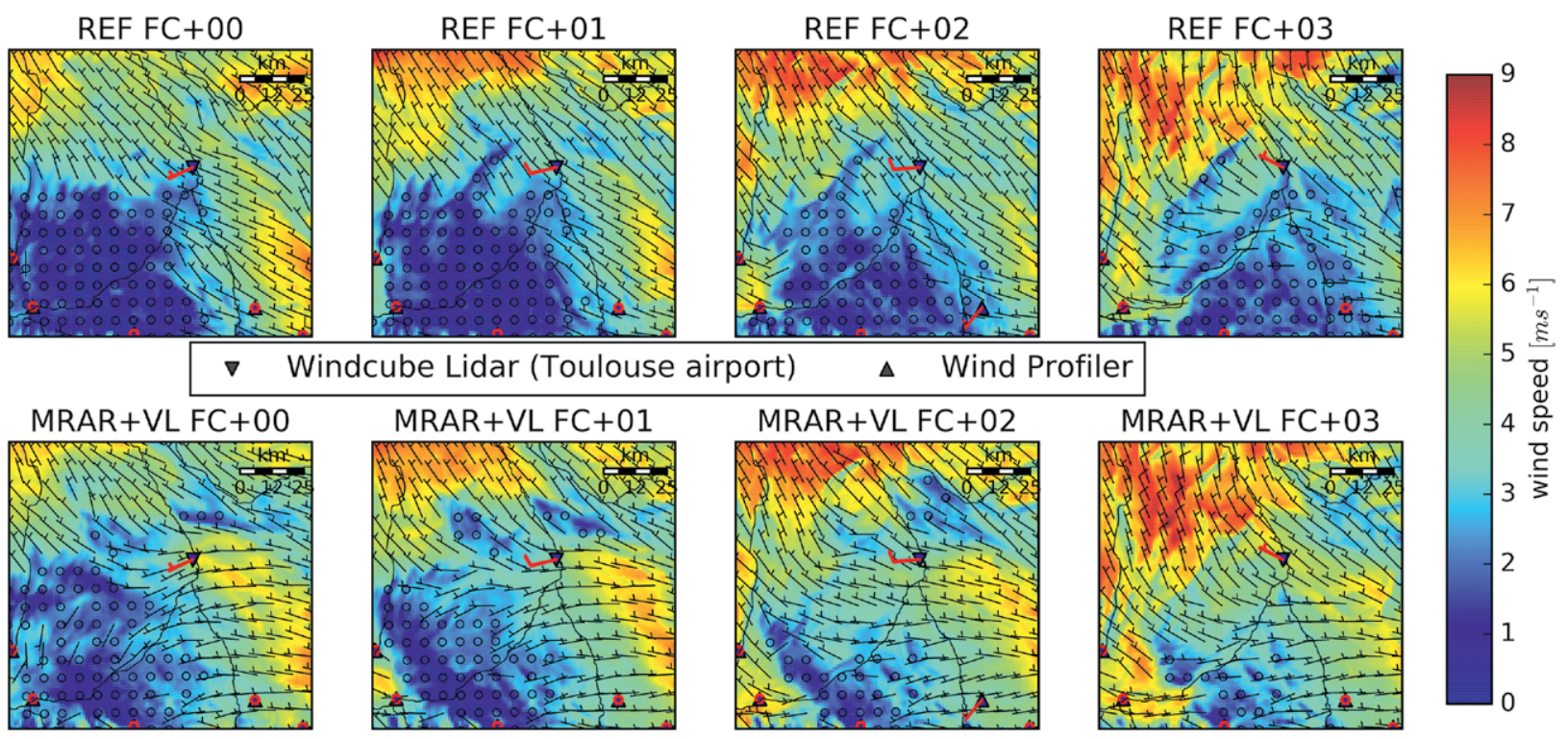

FIG. 10. Wind forecast at approximately $980 \mathrm{hPa}$ of (top) the REF run and (bottom) the MRAR+VL for four forecast times (columns). The colors indicate the wind speed, and the barbs show the wind direction. Also shown are the wind observations (Windcube lidar and wind profiler) valid at the forecast time at approximately the same height. 
CONCLUSIONS. In this article, the main achievements of the UFO project have been presented. The main project objective was to develop a unique set of wind vector and turbulence intensity measurement systems for wake-vortex hazard mitigation. Future dynamic separation concepts rely on such measurements systems, which have the potential to increase airport capacity and improve aviation safety. Therefore, improved estimates of wind vectors and EDR with high update rates and spatial resolution in specific areas are desired, such as the aircraft approach and takeoff flight paths.

Measurement system objectives have been defined that satisfy all the different requirements for surveying wind hazards at airports for current standard operations as well as for future advanced dynamic separation concepts. The analysis made shows that the combination of X-band scanning radar and $1.54-\mu \mathrm{m}$ scanning Doppler lidar is close to an optimal one for all-weather surveying of local wind hazards, taking into account their limitations due to their measurement principles. A prototype of such an optimal remote measurement system that satisfies the requirements mentioned above and allows for "almost" all-weather monitoring of wind vectors and EDR along the aircraft approach and takeoff flight paths has been tested in operational conditions. The prototype includes a $1.54-\mu \mathrm{m}$ scanning Doppler lidar, developed by Leosphere, and an electronically scanning X-band radar, developed by Thales. The combination of lidar and radar will be suitable for most weather conditions, where these two instruments are complementary. There remain challenges for less common weather such as fog (hence almost all-weather monitoring), where the scanning lidar and scanning radar are not useful, and other additional instruments may be necessary.

Different approaches have been taken to reliably estimate wind vectors and EDR from the remote sensors. With regard to the scanning lidar and scanning radar, the main improvements were in the operational performance such as maximum range, and therefore, state-of-the-art retrieval techniques for wind vectors and EDR could be used. The first level of trust in these measurements comes from validation and reliance on other works. During the trials at Toulouse-Blagnac Airport, wind speed and EDR measurements done by the scanning lidar and radar have demonstrated similar values for the two different instruments and thus give confidence. Also, the comparison for wind speed values from different sources showed that wind speed can be obtained reliably in the glide path.
The measurement of EDR from a clear-air profiling radar-the CURIE X-band radar-is a novelty, which required a more dedicated validation effort. Therefore, LES numerical model simulations were used to validate the capabilities and limitations of such an instrument. It was shown that the accuracy of the CURIE X-band radar estimates depends on the level of the EDR, and EDR underestimation by radar-retrieved values increases with the decrease of the EDR. Radar simulations showed that the EDR can be accurately evaluated from the Doppler spectrum of the backscattered signal for $\mathrm{EDR}^{1 / 3}$ values higher than $0.15 \mathrm{~m}^{2 / 3} \mathrm{~s}^{-1}$ for this instrument. In addition, vertical profiles of EDR retrieved by the CURIE radar profiler and a lidar profiler also demonstrated good mutual agreement.

Experiments have demonstrated that both radar and lidar profilers were able to monitor the atmosphere continuously and demonstrate the daily cycle of turbulence and were thus providing valuable valuable estimates of EDR. In particular, it was demonstrated that the CURIE X-band radar was capable of retrieving turbulence intensity during clear-air conditions, which can improve the awareness of hazards due to turbulence. A logical next step to further enhance the trust in these remote sensors is the deployment of a long-lasting project at an airport and test these measurement systems under a wide variety of weather conditions, including comparisons of wind vectors and EDR with in situ measurements.

The second goal of the UFO project-improving high-resolution local weather forecasts by ingesting remote wind measurements into NWP models-was also demonstrated. Mode-S downlinked data have been used to estimate horizontal wind vectors from commercial aircraft, which is proven to be a valuable resource for NWP model forecasts assimilation. With an OSE, the added value of lidar data ingestion in high-resolution NWP models was estimated. A positive impact with MRAR Mode-S and profiling lidar was found, which was present up to $60 \mathrm{~min}$ in the NWP model.

ACKNOWLEDGMENTS. The authors thank the European Commission for funding the UFO European FP7 project and to all partners within the project for their input of expertise and data.

\section{REFERENCES}

Al-Sakka, H., A. Weill, C. Le Gac, R. Ney, L. Chardenal, J. P. Vinson, L. Barthès, and E. Dupont, 2009: CURIE: A low power X-band, low atmospheric boundary 
layer Doppler radar. Meteor. Z., 18, 267-276, https:// doi.org/10.1127/0941-2948/2009/0377.

Barbaresco, F., L. Thobois, A. Dolfi-Bouteyre, N. Jeannin, R. Wilson, M. Valla, and A. Hallermeyer, 2015: Monitoring wind, turbulence and aircraft wake vortices by high resolution RADAR and LIDAR remote sensors in all weather conditions. URSI France Journées Scientifiques 2015, Paris, France, URSI, 81-110, http:// webistem.com/ursi-f2015/output_directory/cd1 /data/articles/000033.pdf.

Boeing, 2013: Statistical summary of commercial jet airplane accidents worldwide operations 1959-2012. Tech. Rep., 26 pp.

Bouniol, D., A. Illingworth, and R. Hogan, 2004: Deriving turbulent kinetic energy dissipation rate within clouds using ground based radar. Proc. Third European Conf. on Radar Meteorology, Visby, Sweden, SMHI, 281-285.

Brewster, K. A., and D. S. Zrnić, 1986: Comparison of eddy dissipation rates from spatial spectra of Doppler velocities and Doppler spectrum widths. J. Atmos. Oceanic Technol., 3, 440-452, https://doi .org/10.1175/1520-0426(1986)003<0440:COEDRF $>2.0 . \mathrm{CO} ; 2$.

Cariou, J.-P., B. Augere, and M. Valla, 2006: Laser source requirements for coherent lidars based on fiber technology. C. R. Phys., 7, 213-223, https://doi .org/10.1016/j.crhy.2006.03.012.

Chan, P. W., 2011: Generation of an eddy dissipation rate map at the Hong Kong International Airport based on Doppler lidar data. J. Atmos. Oceanic Technol., 28, 37-49, https://doi.org/10.1175/2010JTECHA1458.1.

—, C. M. Shun, and K. C. Wu, 2006: Operational LIDAR-based system for automatic windshear alerting at the Hong Kong International Airport. 12th Conf. on Aviation Range and Aerospace Meteorology, Atlanta, GA, Amer. Meteor. Soc., 6.11, https:// ams.confex.com/ams/Annual2006/techprogram /paper_100601.htm.

de Haan, S., 2011: High-resolution wind and temperature observations from aircraft tracked by Mode-S air traffic control radar. J. Geophys. Res., 116, D10111, https://doi.org/10.1029/2010JD015264.

_ 2013: An improved correction method for high quality wind and temperature observations derived from Mode-S EHS. KNMI Tech. Rep. TR-338, 54 pp., www .sciamachy-validation.org/bibliotheek/knmipubTR /TR338.pdf.

— , and A. Stoffelen, 2012: Assimilation of highresolution Mode-S wind and temperature observations in a regional NWP model for nowcasting applications. Wea. Forecasting, 27, 918-937, https:// doi.org/10.1175/WAF-D-11-00088.1.
De Visscher, I., L. Bricteux, and G. Winckelmans, 2013: Aircraft vortices in stably stratified and weakly turbulent atmospheres: Simulation and modeling. AIAA J., 51, 551-566, https://doi.org/10.2514/1.J051742.

Dolfi-Bouteyre, A., and Coauthors, 2009: Pulsed 1.5mm LIDAR for axial aircraft wake vortex detection based on high-brightness large-core fiber amplifier. IEEE J. Sel. Top. Quantum Electron., 15, 441-450, https://doi.org/10.1109/JSTQE.2008.2010463.

Doviak, R. J., and D. S. Zrnić, 1993: Doppler Radar and Weather Observations. 2nd ed. Academic Press, $562 \mathrm{pp}$.

EUROCONTROL, 2013: Performance review report: An assessment of air traffic management in Europe during the calendar year 2013. Performance Review Commission Tech. Rep., 138 pp., www.eurocontrol .int/sites/default/files/publication/files/prr-2013.pdf.

Frehlich, R., S. M. Hannon, and S. W. Henderson, 1998: Coherent Doppler lidar measurements of wind field statistics. Bound.-Layer Meteor., 86, 233-256, https:// doi.org/10.1023/A:1000676021745.

Frisch, A. S., and S. F. Clifford, 1974: A study of convection capped by a stable layer using Doppler radar and acoustic echo sounders. J. Atmos. Sci., 31, 1622-1628, https://doi.org/10.1175/1520-0469(1974)031<1622:AS $\mathrm{OCCB}>2.0 . \mathrm{CO} ; 2$.

Gerz, T., F. Holzäpfel, and D. Darracq, 2002: Commercial aircraft wake vortices. Prog. Aerosp. Sci., 38, 181208, https://doi.org/10.1016/S0376-0421(02)00004-0. Gossard, E. E., D. E. Wolfe, K. P. Moran, R. A. Paulus, K. D. Anderson, and L. T. Rogers, 1998: Measurement of clear-air gradients and turbulence properties with radar wind profilers. J. Atmos. Oceanic Technol., 15, 321-342, https://doi.org/10.1175/1520 -0426(1998)015<0321:MOCAGA>2.0.CO;2.

Hill, R., and S. Clifford, 1978: Modified spectrum of atmospheric temperature fluctuations and its application to optical propagation. J. Opt. Soc. Amer., 68, 892-899, https://doi.org/10.1364/JOSA.68.000892.

Holzäpfel, F., 2006: Probabilistic two-phase aircraft wake-vortex model: Further development and assessment. J. Aircr., 43, 700-708, https://doi.org/10 $.2514 / 1.16798$

— , T. Gerz, F. Köpp, E. Stumpf, M. Harris, R. I. Young, and A. Dolfi-Bouteyre, 2003: Strategies for circulation evaluation of aircraft wake vortices measured by lidar. J. Atmos. Oceanic Technol., 20, 1183-1195, https://doi.org/10.1175/1520-0426(2003)020<1183:SF CEOA>2.0.CO;2.

ICAO, 2005: Manual on low-level wind shear. International Civil Aviation Organization Tech. Doc. 9817 AN/449, 213 pp., www.skybrary.aero/bookshelf/books 12194.pdf. 
— 2007: Procedures for air navigation services: Air traffic management. International Civil Aviation Organization Tech. Doc. 4444 AMT/501, 82 pp.

_ , 2014: 2013-2028 global air navigation capacity \& efficiency plan. International Civil Aviation Organization Tech. Doc. 9750, 137 pp., www.icao.int /Meetings/anconf12/Documents/Draft\%20Doc\%20 9750.GANP.en.pdf.

- 2016: Annex 3 to the Convention on International Civil Aviation. 19th ed. International Civil Aviation Organization, Meteorological Service for International Air Navigation Tech. Doc., 208 pp.

Illingworth, A. J., D. Cimini, C. Gaffard, M. Haeffelin, V. Lehmann, U. Löhnert, E. J. O’Connor, and D. Ruffieux, 2015: Exploiting existing ground-based remote sensing networks to improve high-resolution weather forecasts. Bull. Amer. Meteor. Soc., 96, 2107 2125, https://doi.org/10.1175/BAMS-D-13-00283.1.

Jacoby-Koaly, S., B. Campistron, S. Bernard, B. Bénech, F. Girard-Ardhuin, J. Dessens, E. Dupont, and B. Carissimo, 2002: Turbulent dissipation rate in the boundary layer via UHF wind profiler Doppler spectral width measurements. Bound.-Layer Meteor., 103, 361-389, https://doi.org/10.1023/A:1014985111855.

Kameyama, S., T. Ando, K. Asaka, Y. Hirano, and S. Wadaka, 2007: Compact all-fiber pulsed coherent Doppler lidar system for wind sensing. Appl. Opt., 46, 1953-1962, https://doi.org/10.1364/AO.46.001953.

Klein, A., S. Kavoussi, and R. S. Lee, 2009: Weather forecast accuracy: Study of impact on airport capacity and estimation of avoidable costs. Eighth USA/Europe Air Traffic Management Research and Development Seminar, Napa, CA, FAA/EUROCONTROL, 10 pp., http://atmseminar.eurocontrol.fr/8th-seminar -united-states-june-2009/papers/paper_008/view.

Kolmogorov, A., 1941: Dissipation of energy in locally isotropic turbulence. Dokl. Akad. Nauk SSSR, 32, 16-18.

Kongara, S., R. Calhoun, A. Choukulkar, and M.-O. Boldi, 2012: Velocity retrieval for coherent Doppler lidar. Int. J. Remote Sens., 33, 3596-3613, https://doi .org/10.1080/01431161.2011.631948.

Köpp, F., S. Rahm, I. Smakikho, A. Dolfi, J.-P. Cariou, and M. Harris, 2005: Comparison of wake-vortex parameters measured by pulsed and continuouswave lidars. J. Aircr., 42, 916-923, https://doi.org /10.2514/1.8177.

Koschmieder, H., 1925: Theorie der horizontalen Sichtweite (in German). Beitr. Phys. Freien Atmos., 12, 33-55.

Kovalev, D., D. Vanhoenacker-Janvier, R. Wilson, and F. Barbaresco, 2016: Electromagnetic wind radar simulator validation using meteorological data and a zenith X-band radar. 2016 European Radar Conf., London, United Kingdom, IEEE, 121-124, http:// ieeexplore.ieee.org/stamp/stamp.jsp?tp=\&arnumber $=7811662$ \&isnumber $=7811617$.

Krishnamurthy, R., A. Choukulkar, R. Calhoun, J. Fine, A. Oliver, and K. Barr, 2013: Coherent Doppler lidar for wind farm characterization. Wind Energy, 16, 189-206, https://doi.org/10.1002/we.539.

Kulcsar, G., Y. Jaouen, G. Canat, E. Olmedo, and G. Debarge, 2003: Multiple-Stokes stimulated Brillouin scattering generation in pulsed high-power double-cladding Er/sup 3+/-Yb/sup 3+/-codoped fiber amplifier. IEEE Photonics Technol. Lett., 15, 801-803, https://doi.org/10.1109/LPT.2003.811141.

Kulesa, G., 2003: Weather and aviation: How does weather affect the safety and operations of airports and aviation, and how does FAA work to manage weather-related effects? Potential Impacts of Climate Change on Transportation Workshop, Washington, DC, USDOT, 199-208, www.transportation.gov /sites/dot.gov/files/docs/workshop_0.pdf.

Lombard, L., and Coauthors, 2015: Long range wind lidars based on novel high spectral brilliance allfibered sources., Proc. SPIE, 9645, 96450B, https:// doi.org/10.1117/12.2197350.

Monin, A. S., and A. M. Yaglom, 1975: Statistical Fluid Mechanics: Mechanics of Turbulence. Vol. 2, MIT Press, 886 pp.

Morris, C., J. Peters, and P. Choroba, 2013: Validation of the time based separation concept at London Heathrow Airport. 10th USA/Europe Air Traffic Management Research and Development Seminar, Chicago, IL, FAA/EUROCONTROL, 222, www.atmseminar .org/seminarContent/seminar $10 /$ papers $/ 222$ -CHOROBA_0125130310-Final-Paper-4-11-13.pdf.

Muschinski, A., P. P. Sullivan, D. B. Wuertz, R. J. Hill, S. A. Cohn, D. H. Lenschow, and R. J. Doviak, 1999: First synthesis of wind-profiler signals on the basis of large-eddy simulation data. Radio Sci., 34, 1437-1459, https://doi.org/10.1029/1999RS900090.

Nastrom, G. D., 1997: Doppler radar spectral width broadening due to beamwidth and wind shear. Ann. Geophys., 15, 786-796, https://doi.org/10.1007 /s00585-997-0786-7.

— rates from radar observations at $5-20 \mathrm{~km}$ at White Sands Missile Range, New Mexico. J. Geophys. Res., 102, 19495-19505, https://doi.org/10.1029/97JD01262.

O'Connor, E. J., A. J. Illingworth, I. M. Brooks, C. D. Westbrook, R. J. Hogan, F. Davies, and B. J. Brooks, 2010: A method for estimating the turbulent kinetic energy dissipation rate from a vertically pointing Doppler lidar, and independent evaluation 
from balloon-borne in situ measurements. J. Atmos. Oceanic Technol., 27, 1652-1664, https:/doi. org/10.1175/2010JTECHA1455.1.

Oude Nijhuis, A. C. P., C. M. H. Unal, O. A. Krasnov, H. W. J. Russchenberg, and A. Yarovoy, 2014: Outlook for a new wind field retrieval technique: The 4D-Var wind retrieval. 2014 Int. Radar Conf., Lille, France, IEEE, 1-6, https:/doi.org/10.1109/RADAR.2014 .7060421 .

- O. Krasnov, A. Yarovoy, C. Unal, and H. Russchenberg, 2016a: Implementation of wind vector and turbulence intensity retrievals: Application to fast scanning X-band radar. 2016 IEEE Metrology for Aerospace, Florence, Italy, IEEE, 113-117, https:/doi .org/10.1109/MetroAeroSpace.2016.7573196.

_ , F. Yanovsky, O. Krasnov, C. Unal, H. Russchenberg, and A. Yarovoy, 2016b: Assessment of the rain drop inertia effect for radar based turbulence intensity retrievals. Int. J. Microwave Wireless Technol., 8 , 835-844, https://doi.org/10.1017/S1759078716000660.

Pereira, C., D. Vanhoenacker-Janvier, and F. Barbaresco, 2014: Simulation of X-band radar for the assessment of eddy dissipation rate on a convective boundary layer. Proc. WakeNet-Europe Workshop 2014, Brétigny, France, EUROCONTROL, 20 pp., www.wakenet.eu /fileadmin/user_upload/Workshop2014/Presentations /WakeNetEurope_Workshop2014_603_Pereira.pdf.

Pope, S. B., 2000: Turbulent Flows. Cambridge University Press, $801 \mathrm{pp}$.

Robasky, F. M., and D. A. Clark, 2008: A wind forecast algorithm to support Wake Turbulence Mitigation for Departures (WTMD). 13th Conf. Aviation, Range and Aerospace Meteorology, New Orleans, LA, Amer. Meteor. Soc., 10.2, https://ams.confex.com /ams/88Annual/techprogram/paper_132942.htm.

Salonen, K., S. Niemelä, and C. Fortelius, 2011: Application of radar wind observations for low-level NWP wind forecast validation. J. Appl. Meteor. Climatol., 50, 1362-1371, https://doi.org/10.1175 /2010JAMC2652.1.

Siebert, H., K. Lehmann, and M. Wendisch, 2006: Observations of small-scale turbulence and energy dissipation rates in the cloudy boundary layer. J. Atmos. Sci., 63, 1451-1466, https://doi.org/10.1175/JAS3687.1. Singhal, J., 2014: From SESAR to implementation: Completing the TBS picture. WakeNet-Europe Workshop 2014, Brétigny, France, EUROCONTROL, 19 pp., www .wakenet.eu/fileadmin/user_upload/Workshop2014 /Presentations/WakeNetEurope_Workshop2014_101 _Goodman.pdf.

Sreenivasan, K., 1995: On the universality of the Kolmogorov constant. Phys. Fluids, 7, 2778-2784, https:// doi.org/10.1063/1.868656.
Stoll, S. A., 1991: Microburst detection by the lowlevel wind shear alert system. Weather, 46, 334-347, https://doi.org/10.1002/j.1477-8696.1991.tb07074.x.

Strajnar, B., N. Žagar, and L. Berre, 2015: Impact of new aircraft observations Mode-S MRAR in a mesoscale NWP model. J. Geophys. Res. Atmos., 120, 3920-3938, https://doi.org/10.1002/2014JD022654.

Sutton, O. G., 1953: Micrometeorology: A Study of Physical Processes in the Lowest Layers of the Earth's Atmosphere. McGraw-Hill, 333 pp.

Tatarski, V. I., 1971: The Effects of Turbulent Atmosphere on Wave Propagation. Israel Program for Scientific Translations, $482 \mathrm{pp}$.

Taylor, G. I., 1938: The spectrum of turbulence. Proc. Roy. Soc. London, 164A, 476-490, https://doi.org /10.1098/rspa.1938.0032.

Thobois, L. P., R. Krishnamurty, J.-P. Cariou, A. DolfiBouteyre, and M. Valla, 2015: Wind and EDR measurements with scanning Doppler LIDARs for preparing future weather dependent separation concepts. Seventh AIAA Atmospheric and Space Environments Conf., Dallas, TX, AIAA, AIAA 2015-3317, https://doi.org/10.2514/6.2015-3317.

Wagner, R., and M. Courtney, 2014: Scanning LIDAR verification study-DTU report. Tech. Rep., 81 pp.

Westerhellweg, A., B. Canadillas, A. Beeken, and T. Neumann, 2010: One year of lidar measurements at FINO1-Platform: Comparison and verification to met-mast data. Proc. 10th German Wind Energy Conf., Bremen, Germany, DEWI, 5 pp., www.dewi .de/dewi/fileadmin/pdf/publications/Publikations /S01_3.pdf.

White, A. B., R. J. Lataitis, and R. S. Lawrence, 1999: Space and time filtering of remotely sensed velocity turbulence. J. Atmos. Oceanic Technol., 16, 1967-1972, https://doi.org/10.1175/1520-0426(1999)016<1967:SA TFOR $>2.0 . C O ; 2$.

Wieringa, J., 1980: Representativeness of wind observations at airports. Bull. Amer. Meteor. Soc., 61, 962-971, https://doi.org/10.1175/1520-0477(1980)061<0962:RO WOAA $>2.0 . \mathrm{CO} ; 2$.

Williams, D. M., G. W. Lohr, and A. C. Trujillo, 2008: Wake Turbulence Mitigation for Arrivals (WTMA). 26th Int. Congress of the Aeronautical Sciences, Anchorage, AK, International Council of the Aeronautical Sciences, 10 pp., https://ntrs.nasa.gov/archive /nasa/casi.ntrs.nasa.gov/20080040152.pdf.

Wilson, R., 2004: Turbulent diffusivity in the free atmosphere inferred from MST radar measurements: A review. Ann. Geophys., 22, 3869-3887, https://doi .org/10.5194/angeo-22-3869-2004.

WMO, 2010: Technical regulations: Volume II-Meteorological service for international air navigation. 
WMO-49, 180 pp., https://library.wmo.int/pmb_ged /wmo_49-v2_2013_en.pdf.

Wolfson, M., and Coauthors, 1990: Characteristics of thunderstorm-generated low altitude wind shear: A survey based on nationwide terminal Doppler weather radar testbed measurements. 29th IEEE Conf. Decision and Control, Honolulu, HI, IEEE, 682-688, https://doi.org/10.1109/CDC.1990 .203681 .
Yanovsky, F., H. Russchenberg, and C. Unal, 2005: Retrieval of information about turbulence in rain by using Doppler-polarimetric radar. IEEE Trans. Microwave Theory Tech., 53, 444-450, https://doi .org/10.1109/TMTT.2004.840772.

Zhang, X., W. Diao, Y. Liu, J. Liu, X. Hou, and W. Chen, 2014: Single-frequency polarized eye-safe all-fiber laser with peak power over kilowatt. Appl. Phys. B, 115, 123-127, https://doi.org/10.1007/s00340-013-5582-3.

\section{The Thinking Person's Guide to Climate Change}

\section{Robert Henson}

Expanded and updated from Henson's Rough Guide to Climate Change, 3rd edition (no longer in print), combining years of data with recent research, including conclusions from the Fifth Assessment Report of the Intergovernmental Panel on Climate Change, the Guide breaks down the issues into straightforward categories:

$>\quad$ Symptoms, including melting ice and extreme weather

$>$ Science, laying out what we know and how we know it

$>$ Debates, tackling the controversy and politics

$>$ Solutions and Actions for creating the best possible future

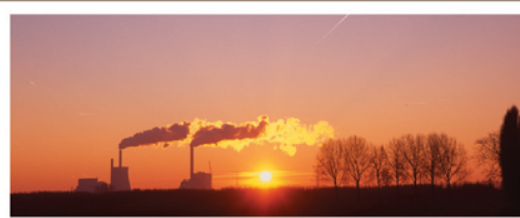

\section{ROBERT HENSON}

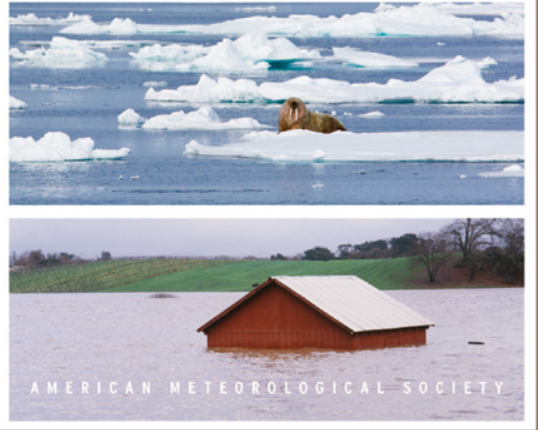
M MS AMS BOOKS RESEARCH APPLICATIONS \ HISTORY

> bookstore.ametsoc.org 


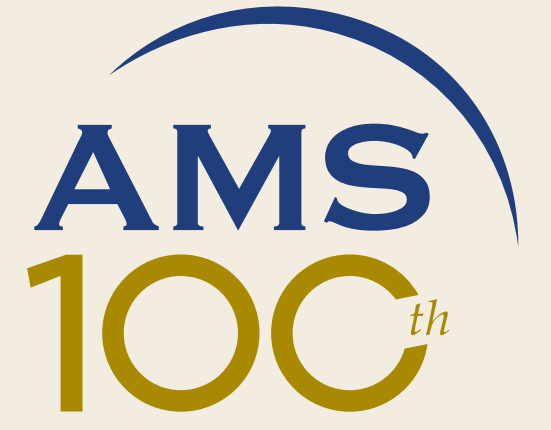

Anniversary Campaign Imagine the potential Engage the world Empower the future

\section{Help us \\ empower the future of the atmospheric, oceanic, and hydrologic sciences}

In 2019, AMS will celebrate our 100th Anniversary. To mark this incredible milestone, we're inviting our members and others across the weather, water, and climate community to join us in supporting the future success of scientists, professionals, students, educators, broadcasters and others committed to using science to make the world a better place.

The AMS 100th Anniversary Campaign is raising funds in critical areas to ensure our fields of science are well-positioned to help meet the challenges of a changing world. There are a number of ways to contribute either now or as future giving.

Please consider giving to any of our campaign funds:

- Rapid Adaptation

- Breakthrough Science

- Engaging the Public

- Bridging Disciplines

- Globalization

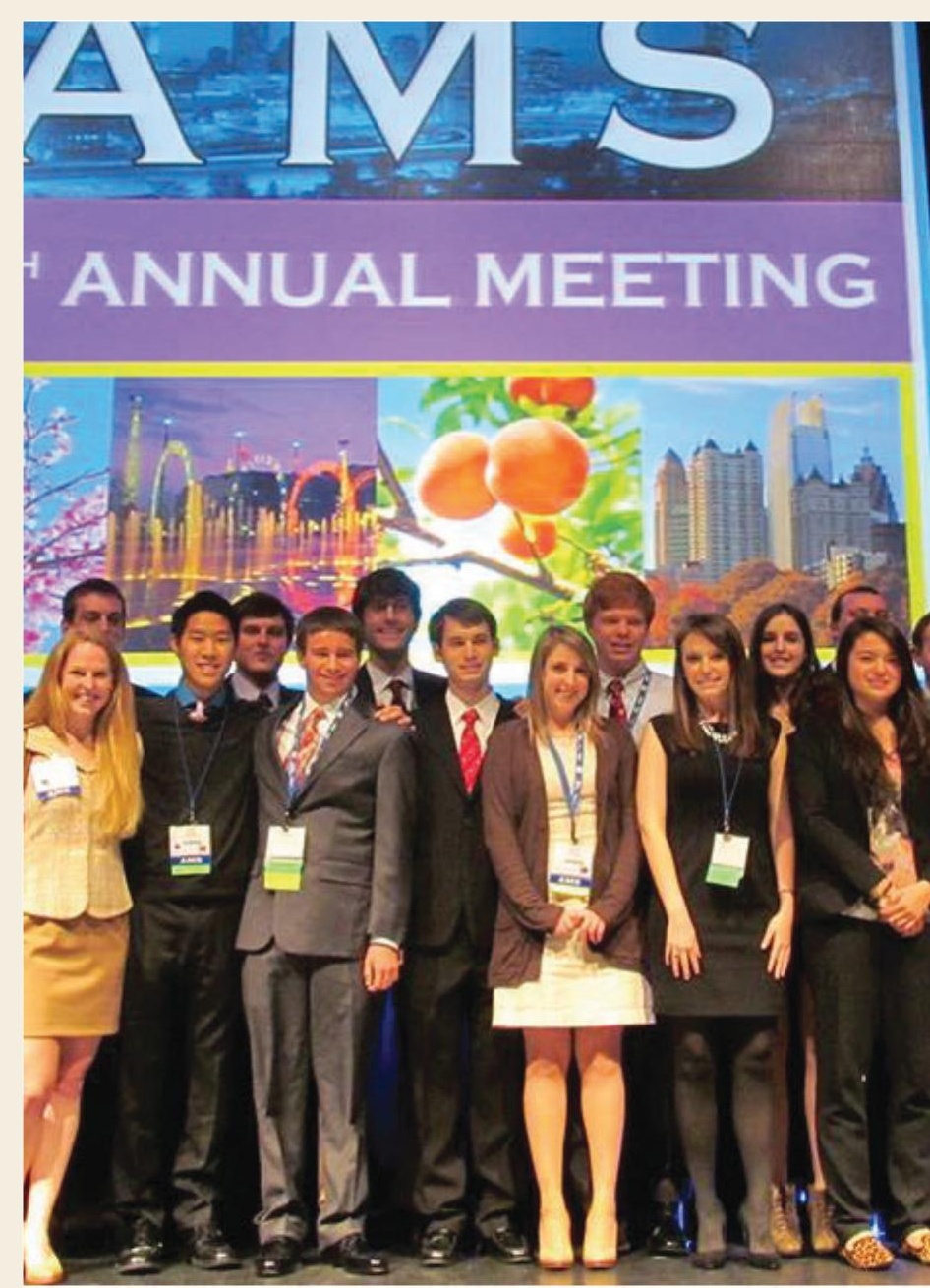

\section{ametsoc.org/give}

